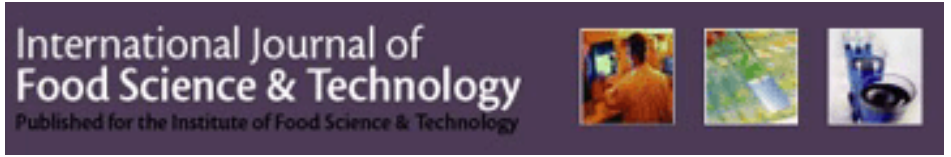

\title{
On-farm evaluation of the impact of drying and storage on the carotenoid content of orange-fleshed sweet potato (Ipomea batata Lam.)
}

\begin{tabular}{|r|l|}
\hline Journal: & International Journal of Food Science and Technology \\
\hline Manuscript ID: & IJFST-2010-06241.R2 \\
\hline Manuscript Type: & Original Manuscript \\
\hline Keywords: & $\begin{array}{l}\text { Sweet Potatoes, Drying, Kinetics, Vitamin A, Beta Carotene, Shelf } \\
\text { Life }\end{array}$ \\
\hline \multicolumn{2}{|c}{} \\
\hline
\end{tabular}

\section{SCHOLARONE} Manuscripts 
1 On-farm evaluation of the impact of drying and storage on the

2 carotenoid content of orange-fleshed sweet potato (Ipomea batata

$3 \quad$ Lam.)

4 Running head: On-farm carotenoid loss in sweet potato chips 5

6 Aurélie Bechoff ${ }^{1^{*}}$, Keith Tomlins ${ }^{1}$, Claudie Dhuique-Mayer ${ }^{2}$, Richard Dove ${ }^{3}$ and 7 Andrew Westby ${ }^{1}$

$8{ }^{I}$ Natural Resources Institute, University of Greenwich, Central Avenue, Chatham Maritime,

9 Kent ME4 4TB, United Kingdom.

$10{ }^{2}$ Centre International de Recherche Agronomique pour le Développement (CIRAD) UMR

11 Qualisud, TA 95B/16, 34398 Montpellier, France

$12{ }^{3}$ HarvestPlus Reaching End Users Project, World Vision, CP 517, Rua de Resistencia, 13 Quelimane, Mozambique

14 *Correspondence to: Aurelie Bechoff, Natural Resources Institute (NRI), University of Greenwich, Central Avenue, Chatham, Kent ME4 4TB, UK. Email: a.bechoff@gre.ac.uk

17 Abstract: Drying of orange-fleshed sweet potato was evaluated under African rural 18 conditions. Three locally-built dryers (open air-sun; tunnel and shade) were tested using 19 Resisto and MGCL01 varieties in Mozambique. Total carotenoid losses were low in all dryers 20 being $9.2 \%$ on average. After drying sweet potato chips were stored in a traditional way (jute 21 bags inside a mud house). Chip size (thin, thick chip or slice) had a significant effect on 22 drying $(\mathrm{p}<0.05)$ but not on storage; and variety had an effect on both. Total carotenoid losses 23 during storage were much higher being $83.7 \%$ on average, after four months, with main 24 individual carotenoids fitting a first order kinetics degradation. Globally carotenoid losses on25 farm or on-research station, were of similar level. 
26 Keywords: Ipomea batata (L.) Lam, carotenoids, storage, drying, on-farm, on-research.

27

\section{INTRODUCTION}

Mozambique is one of the poorest countries in the world, and additionally, one of the most affected by vitamin A deficiency; $71 \%$ of the children under five are deficient (Aguayo \& Baker, 2005). White-fleshed sweet potato (WFSP) is traditionally part of the Mozambican diet, as a source of carbohydrate. An integrated agricultural and nutritional intervention involving households with young children in rural areas of Mozambique has demonstrated that regular consumption of orange-fleshed sweet potato (OFSP), rich in $\beta$-carotene, significantly improved the vitamin A status of the children (Low et al., 2007). The marketing and consumption of OFSP in Mozambique has increased as a result of initiatives by Centro Internacional de la Papa (CIP) and Instituto de Investigação Agrária de Moçambique (IAAM), and recent promotion programmes, such as the HarvestPlus Reaching End Users Project (2006-2010). New ways of consuming OFSP in forms such as juice, bread and confectionary products are being investigated in order to extend the availability and nutritional benefits through both home consumption and trade. The availability of fresh sweet potato is seasonal and storage of the fresh root beyond 3 months is difficult (Tomlins et al., 2007). Hence the production of dried products could potentially extend the availability of sweet potato by up to 4-6 months. Sun-drying of sweet potato is a traditional processing practice in many developing countries including a number of African countries (Woolfe, 1992). Although sundrying of sweet potato has been reported in Mozambique (Dove R., pers. comm.), reports have been scarce. A World Vision survey for OVATA in Zambezia district, Mozambique (van Straaten, 2006) indicated that about 35\% of households who grow sweet potato also practiced drying of sweet potato. Sun-drying is a non-controlled technology and previous studies on a range of commodities have demonstrated that the level of drying technology used 
51 has an impact on provitamin A carotenoid retention (Bechoff et al., 2009; Chen et al., 2007;

52 Desorby et al., 1997; Mulokozi \& Svanberg, 2003; Negi \& Roy, 2000). Sun-drying could 53 result in higher carotenoid losses than with other technologies, such as solar-drying 54 (Mulokozi \& Svanberg, 2003; Negi \& Roy, 2000). However recent publications (Bengtsson et 55 al., 2008; Bechoff et al., 2009; Bechoff et al., 2010a) have showed that carotenoid losses 56 from sweet potato chips during sun-drying were low and were similar to solar-drying. In 57 addition, it was demonstrated in an on-station study in Uganda (Bechoff et al., 2010a), that 58 losses of carotenoids were much more critical during storage for four months (70.4\%) than during drying (9.0\%). Tomlins et al. (2007) argued that experimental results obtained on a

60 research station do not necessarily transfer to the farm situation because of variations in 61 farmer knowledge and the local environment. It was therefore important to verify the on62 station results in typical rural setting.

In order to better preserve provitamin A in sweet potato drying, there was a further need to determine whether process variables influence carotenoid degradation and the rate of 66 degradation during storage. In an on-farm study, variables that can be straightforwardly 67 explored are sweet potato chip size and variety. In laboratory trials, chip size has been 68 reported to influence carotenoid degradation in sweet potato during sun-drying (Bechoff et $69 a l ., 2009)$ and the variety of sweet potato has also been reported to influence carotenoid 70 degradation (Bechoff et al., 2010a). Determination of kinetics of carotenoid degradation in 71 dried sweet potato during storage under laboratory conditions has been reported in literature 72 (Haralampu \& Karel, 1983; Stephanovitch \& Karel, 1982) but field studies measuring 73 carotenoid kinetics in dried food commodities such as sweet potato are scarce. The 74 determination of carotenoid degradation rate under on-farm conditions could bring a practical 
75 help to farmers and millers with the evaluation of dried OFSP shelf life that could potentially 76 lead to an improvement of the product quality.

77 The aim of the study was to evaluate simple and low-cost drying and storage for orange78 fleshed sweet potato (OFSP) on-farm. The main objective was to measure the level of 79 carotenoid loss after solar and sun drying and over a four-month storage period taking into 80 account the effect of variety and chipping.

81

82 MATERIALS AND METHODS

83 Root samples

84 Mature sweet potato roots (MGCL01 and Resisto varieties), about $80 \mathrm{~kg}$ per variety, were 85 purchased from farmers around Lualua, Zambézia Province, Mozambique (105 km from 86 Quelimane, the Province Capital). The exact root harvest age was not known. All roots were 87 processed within one to three days after harvest.

\section{Dryers}

89 Three dryers were constructed on a farm belonging to a subsistence farmer at Lualua. Apart 90 from the greenhouse clear plastic (Strawberry 3 seasons BPI-VISQUEEN®, UK thickness $91150 \mu \mathrm{m}$ ), all building materials were obtained locally and constructed by local craftsmen. 92 Each of the dryers was mounted on a simple wooden structure that was fitted with straw mats.

93 - The tunnel dryer had similar dimensions to the on-research station dryer in Uganda (Bechoff 94 et al., 2010a). It had a total length of $9 \mathrm{~m}$ and a width of $1.5 \mathrm{~m}$. The collector (absorber) 95 occupied the first $3.5 \mathrm{~m}$ and was formed of an iron metal sheet. The rest of the dryer (5.5 m) 96 was used as drying area. The floor of the drying area was made of straw mats covered with 97 black plastic sheeting to insulate the structure. Clear greenhouse plastic covered the whole 
98 structure apart from the inlet and outlet allowing air flow and protected by mosquito net $99\left(0.55 \mathrm{~m}^{2}\right.$ each $)$. The dryer had a $6^{\circ}$ slope.

100 - The open air dryer (exposed to direct sun) had a length of $6 \mathrm{~m}$ and a width of $1.5 \mathrm{~m}$ with a 101 height of $0.9 \mathrm{~m}$ and had a $6^{\circ}$ slope.

102 - The shade dryer was identical to the open air dryer and with the addition of a grass lined 103 roof. The roof was about $0.6 \mathrm{~m}$ larger and longer than the table in order to protect it from sun 104 light. The shade dryer was flat (i.e. without a $6^{\circ}$ slope) because of building constraints.

105 - Each dryer could fit 6 trays of $4 \mathrm{~kg}$ fresh sample each and surface area per tray was $1.03 \mathrm{~m}^{2}$.

106 The geographical position of the dryers was determined using GPS (GPS 60, GARMIN®).

107 Dryers were positioned facing north; this allowed maximum sun exposure in the southern

108 hemisphere. Temperature/humidity dataloggers (Tinytalk 2 Geminidatalogger, Chichester, 109 UK) were placed in the tunnel dryer and under the shade for ambient temperature 110 measurement.

111 Drying

112 Drying trials were carried out in duplicate on different days (one day and three days after 113 harvest). Roots were washed and spread on a black plastic under the shade for draining. Five 114 fresh roots per variety were collected for carotenoid analysis. On the drying day, unpeeled 115 roots were chipped using either a mechanical rotary disc chipper producing either thick and 116 thin chips, or were hand-sliced (traditional way). Size (thickness, width, length) of ten fresh 117 chips or slices was recorded using a digital calliper. Samples (4 kg) were weighed (Hanson 118 Electronic Chrome Effect Scale; $\pm 1 \mathrm{~g}$ ) after careful mixing (using a quartering technique). All 119 preparation operations were carried out in the shade to minimize losses in carotenoids. Sweet 120 potato samples were evenly spread on mosquito mesh trays (6 trays per dryer) at a density of

$1213.9 \mathrm{~kg} \cdot \mathrm{m}^{-2}$. Loading time was recorded for each dryer. Samples were weighed and turned 122 frequently during drying. Samples were left overnight in the dryers because rain was unlikely 
123 at the time of the study. Under these field conditions, the end of drying was evaluated

124 subjectively by the presence of flour and a characteristic cracking noise when crushed in the 125 hand. The fresh samples of chips/slices per treatment with an initial weight of $4 \mathrm{~kg}$ (per 126 sample) reached a final weight of $1.5 \mathrm{~kg}$ for MGCL01 and $1.0 \mathrm{~kg}$ for Resisto after drying.

\section{Collection of dried sweet potato chips for analysis and storage}

128 A carefully mixed portion of dried chips/slices (about $200 \mathrm{~g}$ ) was collected in zip-polythene 129 bags and placed in a cooler bag before they were transported (within a couple of hours) to a 130 freezer $\left(-20^{\circ} \mathrm{C}\right)$ in Quelimane. The remainder of the chips/slices were used for the storage 131 study (at ambient temperature). Samples were stored in traditional bags made of jute and hung 132 inside a house constructed from mud in Lualua. In order to measure losses during storage, 133 sub-samples (200 g chips or slices per stored sample) were removed respectively after 1 134 month (31 days), 2 months (62 days) and 4 months (125 days) and placed in polythene bags in 135 a cooler bag and quickly transferred and stored in the freezer. The datalogger recording the 136 ambient temperature during storage was unfortunately lost, but it is estimated from records 137 taken nearby in Quelimane that the temperature in the mud house was on average $25{ }^{\circ} \mathrm{C}$ with 138 minimum/maximum temperatures of $20 / 31^{\circ} \mathrm{C}$ (Weather Underground Quelimane, 2007).

\section{Carotenoid analysis}

140 Chip samples in zip bags were stored at $-20^{\circ} \mathrm{C}$ for $1-6$ months before analysis because of 141 delays and the low sample throughput for this method. No significant carotenoid loss was 142 observed on chips in freezer in this interval $(\mathrm{p}<0.05)$ (Bechoff 2010). Samples were milled 143 into flour (particle sizes of less than $1 \mathrm{~mm}$ ) using a Laboratory mill 3600 (Perten Instruments,

144 Segeltorp, Sweden) and extracted in duplicate in a randomised order. Carotenoids were 145 identified and quantified using the method described by Bechoff et al. (2010b). The extraction 146 stage was adapted from Rodriguez-Amaya and Kimura (2004). A portion of the homogeneous 
147 representative sample (0.4-2.0 $\mathrm{g}$ of flour) was re-hydrated for $20 \mathrm{~min}$ in $10 \mathrm{ml}$ deionised 148 water, homogenised with 50mL methanol:tetrahydrofuran (THF) (1:1) for 1 minute and 149 filtered. The homogenised extract was rinsed with methanol:THF (1:1) until there was no 150 yellow colour left in the filtrate. Partition between the aqueous phase and organic phase 151 containing the carotenoids was achieved by addition of petroleum ether $\left(\mathrm{PE}-40-60^{\circ} \mathrm{C}\right)$. The 152 PE phase was further washed with water, dried by addition of anhydrous sodium sulphate, 153 then filtered and made up to volume $(50 \mathrm{ml})$. For the determination of total carotenoid 154 content, absorbance was measured at $450 \mathrm{~nm}$ using a diode array Hewlett Packard 8452A 155 spectrophotometer. For the determination of individual carotenoids by HPLC, the carotenoid 156 extracts in PE were dried by flushing with nitrogen in a dry block system at $35^{\circ} \mathrm{C}$. The 157 extracts were dissolved in $1 \mathrm{ml}$ dichloromethane:MTBE (methyl tert-butyl ether): methanol 158 50:40:10. Reverse-phase high performance liquid chromatography using an Agilent 1100 159 system (Massy, France) was used following the method of Dhuique-Mayer et al. (2007). 160 Carotenoids were separated through a $\mathrm{C}_{30}$ reverse phase column $(250$ x $4.6 \mathrm{~mm}$ i.d.) packed 161 with $5 \mu \mathrm{m}$ YMC (EUROP GmbH, Germany) at a flow rate of $1 \mathrm{ml} \cdot \mathrm{min}^{-1}$, a column 162 temperature at $25^{\circ} \mathrm{C}$ and an injection volume of $20 \mu \mathrm{l}$. Concentrations were determined by 163 comparison to a standard curve using pure $\beta$ - carotene (Extrasynthese, Genay, France).

165 Dry matter determination

166 Samples were collected for dry matter determination, before and after drying at the same time 167 as for carotenoids analysis. Determinations were made by drying triplicate $5 \mathrm{~g}$ samples at 105 $168{ }^{\circ} \mathrm{C}$ to constant weight (minimum 24h) (AOAC, 1984). 
169 Statistical analyses and calculation of carotenoid degradation rates

170 Normality of sample distribution was tested using Shapiro-Wilk and Kolmogorov Smirnov 171 tests $(\mathrm{p}<0.05)$. Analysis of variance (ANOVA) was carried out to determine whether there 172 were significant differences between samples with one up to four factors. A significant 173 difference between samples was determined by a Tukey test. Data were processed on SPSS 17415.00 (SPSS UK Ltd. Woking, Surrey, UK) for Windows software.

176 Linear regression (on Excel) was used to determine the rate of degradation $\mathrm{k}$ following the 177 formula $C=C_{0}-k t$ (zero order kinetics) or $\ln C=\ln C_{0}-k t$ (first order kinetics) where $\mathrm{C}_{0}$ 178 is the total carotenoid content after drying $\left(\mu \mathrm{g} \cdot \mathrm{g}^{-1}\right)$; C the total carotenoid content at storage 179 time $\mathrm{t}\left(\mu \mathrm{g} \cdot \mathrm{g}^{-1}\right) ; \mathrm{k}$ the rate constant $\left(\mathrm{days}^{-1}\right)$ and $\mathrm{t}$ the storage time (days).

180

RESULTS AND DISCUSSION

\section{Effect of dryer on total carotenoid loss}

184 Independently of the dryer or variety, average total carotenoid loss during drying was $9.2 \%$.

185 In all cases, levels of loss were less than $24.6 \%$ (Table 1). Effect of different factors (new 186 chipper and traditional slicing) and three dryers (shade; sun; tunnel) on the two varieties was 187 evaluated on total carotenoid losses (Table 2). The type of dryer had a significant effect $188(\mathrm{p}<0.01)$ on total carotenoid loss. Because control over drying was limited in these field 189 conditions, dry matter was included as covariate in the analysis of variance from data 190 presented in Table 2. The three dryers gave significantly different results of loss: on average 191 there were $13.0 \%, 10.0 \%$ and $1.9 \%$ for the tunnel dryer; open air dryer and shade dryer 192 respectively (Table 1 ). Slight but significantly lower retention of total carotenoids in the 193 tunnel dryer compared to the open air dryer could be explained by the higher temperature 
194 during drying (up to $55^{\circ} \mathrm{C}$ whilst the ambient temperature did not go above $33^{\circ} \mathrm{C}$ ) (Table 1 ).

195 There was furthermore an issue with moisture evacuation from the product in the tunnel 196 dryer, which is illustrated by the maximum $100 \%$ relative humidity reached at night. This 197 may have resulted from a disadvantageous wind direction at this time of the year, blowing 198 East-West, whereas the tunnel was positioned North-South. As compared with the on-station 199 study (Bechoff et al., 2010a) using a similar but optimally oriented tunnel dryer, the on-farm 200 tunnel dryer showed some technical limitations in terms of air flow circulation. In terms of 201 carotenoid losses, the difference in the tunnel and open-air sun dryers (using chips of the same size) was not significant $(9.0 \%$ for the tunnel and open-air sun dryers in the earlier on-station study) (Bechoff et al., 2010a) and small (13\% and 10\% respectively working with thin chips 204 in this on-farm study). The tunnel dryer however protected against insects and rain. This type 205 of dryer was mostly designed for experimental use and, because its cost was estimated to be 206 ten times the cost of an open air dryer and five times that of a shade dryer, mainly due to 207 imported materials, it would not be a feasible proposition for Mozambican farmers to adopt. 208 The open air and shade dryer would be the dryers most suited to rural situation in 209 Mozambique because of their improved carotenoid retention, lower cost and availability of 210 most materials locally (on the farm or in the next village).

212 Complete protection from sun light and lower temperatures for shade-drying compared to 213 tunnel and open air sun dryers can explain the improved carotenoid retention from shade 214 drying. In this study, from an overall product quality perspective, the shade dryer worked well 215 with thin chips but was not well adapted to handcut slices (traditional way) because of longer 216 drying times leading to off-odours. Researchers, working with different commodities, have 217 reported conflicting results regarding carotenoid losses during shade-drying. Chavez et al. 218 (2007) reported that shaded-dried yellow cassava that contained carotenoids had improved 
219 carotenoid retention compared to sun-dried one, while Negi \& Roy (2000), working on leafy 220 vegetables, reported that higher carotenoid losses were obtained in shade and sun-drying as 221 opposed to solar (cabinet) drying. Theses inconsistencies in the literature could be the result 222 from different environmental conditions (temperature, humidity and wind) and different 223 product characteristics influencing carotenoid retention during drying.

\section{Effect of chipping on total carotenoid loss after drying}

226 Traditional slices, thick and thin chips had an average thickness of about $5.2 \mathrm{~mm}, 2.9 \mathrm{~mm}$ and $2270.4 \mathrm{~mm}$ respectively. The effect of chipping treatment using three chipping treatment is 228 reported in open air drying for both MGCL01 and Resisto varieties (Table 1). There was no 229 difference between the thin chips and slices but drying thick chips resulted in significantly 230 higher loss than the other chipping methods, respectively $14.6 \%$ for thick chips and $10.7 \%$ for 231 thin chips; $9.3 \%$ for traditional slices $(\mathrm{p}<0.01)$ (Table 3$)$. Greater losses of total carotenoids in 232 thick chips compared to thin chips could be explained by inadequate chip size: with a small 233 surface area to volume ratio, thick chips may have evacuated moisture less efficiently and the 234 core of the chips may have been less protected during drying. Longer drying times were 235 associated with greater losses of carotenoids during drying of sweet potato (Bechoff et al. 236 2007). Bechoff et al. (2009) working on OFSP also reported that surface area of chip resulted 237 in differential carotenoid loss in sun-drying. In the drying of carrots Wang \& Xi (2005) 238 reported that $\beta$-carotene degradation increased with sample thickness and was also linked to 239 moisture content reached. In the case of slices, reasons might have been different. Greater 240 losses of total carotenoids in thick chips compared to slices could be explained by the greater 241 damage of tissues due to mechanical chipping as opposed to manual slicing. More 242 investigation is still needed to understand the relationships between chip surface/volume, 243 moisture evacuation and carotenoid loss during drying. 
244 Effect of variety on total carotenoid loss after drying

245 Sweet potato variety had a significant impact on total carotenoid loss $(\mathrm{p}<0.01)$. Resisto, with a 246 dry matter content of $27.0 \%$, lost more carotenoids (mean loss of 13.2\%) than MGCL01 with 247 a dry matter of $35.4 \%$ (mean loss of 5.2\%) (Table 1). A similar trend of higher dry matter 248 varieties being associated with lower carotenoid losses was reported by Bechoff et al. (2010a) 249 in on-station trials with six OFSP varieties. This difference between losses in Resisto and 250 MGCL01 varieties might result from difference between dry matter contents that would 251 influence the drying process.

\section{Effect of chipping on total carotenoid loss during storage}

254 Overall average losses in carotenoids from stored chips and slices after one month; two and 255 four months of storage are presented in Figure 1. No effect of chipping was reported when 256 analysing thin, thick chips and slices during storage (ANOVA; $\mathrm{p}<0.01$ ). The lack of 257 interaction between chipping and storage time confirmed that there was consistently no effect 258 of chipping throughout the storage period. Working on pure $\beta$-carotene encapsulated in 259 dextrose equivalent maltodextrin by three drying processes: spray, drum and freeze drying, 260 Desorby et al. (1997) found that larger particles obtained in drum drying had improved $\beta$ 261 carotene stability over storage when compared with the other processes. Mills \& Hart (1945) 262 working on dehydrated sweet potato also found that six month-stored flour had higher 263 carotene loss than sliced material at ambient temperature and concluded that sweet potato 264 should be stored in the way they are dehydrated rather than milled into flour. In the present 265 study, the lack of difference from chipping, however, did not agree with the results by 266 Desorby et al. (1997) and Mills \& Hart (1945), but it is believed that the difference in 267 retention observed in these previous studies is a result of the very different particle sizes of 268 samples tested (i.e. flour and slices) that may have resulted in differential porosity to air 
269 oxidation. This present study demonstrated that there was no effect of chip size in stored 270 samples. Oxidation is reported as the main factor responsible for carotenoid degradation 271 during storage of dried sweet potato (Emenhiser et al., 1999). Therefore the lack of 272 differences in this study is hypothesised to result from similar air oxygen diffusion through 273 the different chip/slice sizes (that did not differ as much in size as with flour and slices) of the 274 samples stored in jute bags.

276 Effect of variety on total carotenoid loss during storage

277 There was a significant effect of variety during storage of dried sweet potato $(\mathrm{p}<0.01)$. Resisto 278 with $26.8 \%, 47.8 \%, 78.6 \%$ loss after one month, two and four months of storage, had lower 279 total carotenoid losses than the MGCL01 variety with $39.0 \%, 63.2 \%, 87.7 \%$ respectively 280 (Figure 1). This could possibly result from differential composition in other constituents that 281 can enhance or delay carotenoid degradation: for instance, enhancers could be unsaturated 282 fatty acids that are mostly linoleic and linolenic acids in sweet potato (Walter \& Purcell, 283 1974) and were related to lipid peroxidation (Arya et al., 1979), and inhibitors of carotenoid 284 oxidation could be phenolic compounds. Phenolic content has been positively correlated to 285 antioxidant activity in various sweet potato varieties (Teow et al., 2007). More investigation 286 is required to understand varietal differences with regard to carotenoid retention.

288 Estimation of vitamin A activity in chips after drying and storage

289 Immediately after drying, average total carotenoid contents for Resisto and MGCL01 290 respectively were $355.6 \mu \mathrm{g} \cdot \mathrm{g}^{-1}$ and $218.2 \mu \mathrm{g} \cdot \mathrm{g}^{-1}$ on a dry weight basis. According to Bechoff 291 et al. (2010a), these values corresponded to an estimated vitamin A activity of 24617 and 15 292107 RE. $\mathrm{kg}^{-1}$ respectively and were largely beyond the recommended daily allowance for 293 children (4000 RE.kg ${ }^{-1}$ ). After a four month-storage, average total carotenoid contents for 
294 Resisto and MGCL01 were $73.4 \mu \mathrm{g} \cdot \mathrm{g}^{-1}$ and $25.9 \mu \mathrm{g} \cdot \mathrm{g}^{-1}$ on a dry weight basis respectively. 295 These values corresponded to an estimated vitamin A activity of 5080 and 1796 RE. $\mathrm{kg}^{-1}$ 296 respectively. After four month-storage the vitamin A activity is strongly reduced and only 297 Resisto variety meets the RDA. However because of other quality issues (i.e. presence of 298 insects) the recommended storage period should not exceed 3 months for Resisto. In order to 299 meet the RDA, the storage time for MGCL01 should not be over two months. These estimates 300 however do not take into account losses occurring during the further processing of dried sweet 301 potato into a form eaten by consumers. This should be the subject of another research study.

Identification of carotenoids before and after storage

303 The individual carotenoid compounds before drying, after drying and after 4 month-storage of 304 dried sweet potato were tentatively identified by HPLC (Figure 2). Resisto had the same 305 chromatographic profile as MGCL01. Therefore only the chromatograms for Resisto are 306 shown. The main compound is trans- $\beta$-carotene (peak 7) resolved at $37 \mathrm{~min}$. and representing $30784 \%$ of the total carotenoid concentration, both for Resisto and MGCL01 samples on average 308 (over dried and stored samples). Other peaks were minor compounds mostly degradation 309 products of all-trans- $\beta$-carotene and even present in fresh root samples in very small 310 quantities. The presence of $\beta$-carotene 5,6 epoxide has been reported by Kósambo et al. 311 (1998) in fresh sweet potato roots. On average (for dried and stored sliced Resisto variety) 312 percentages were the followings; $\beta$-carotene 5,6-epoxide (4.0\%), 5,6-epoxide (3.2\%) 9-cis $313(1.3 \%)$ and 13-cis- $\beta$-carotene (3.1\%). Trans- $\beta$-carotene, $\beta$-carotene 5,6-epoxide, 9 -cis and 13314 cis- $\beta$-carotene were previously identified using the same HPLC system on a different sweet 315 potato variety (Bechoff et al., 2009). In spite of the degradation of $\beta$-carotene, no clear 316 increase of degradation products was readily observed using the HPLC technique. There are 317 minor differences between the chromatographic profiles of those samples, fresh (Figure 2A) 318 or dried (Figure 2B) or dried and subsequently stored (Figure 2C): peaks a (possibly $\beta$ - 
319 carotene-5,6,5',6'-diepoxide); b (possibly $\beta$-carotene-5,6,5', ,'-diepoxide) were found in fresh 320 roots, peaks a, b and c (25 min.unidentified) were found in dried chips but peak c was only 321 detected after four months of storage. Peak 2 ( $\beta$-carotene 5,6 epoxide) was not affected by 322 drying but was sharply reduced during storage. On the other hand, peaks 3 ( $\beta$-carotene 5,8 323 epoxide) and 6 (13-cis $\beta$-carotene) decreased at a lower rate during storage. Storage affected 324 more the chromatographic profile of carotenoids than drying did. Harsher conditions of 325 processing may be necessary to induce more differences in the carotenoid profile. In contrast 326 to this study, significant differences in the chromatographic profile of fresh and heated citrus 327 juices $\left(5 \mathrm{~h} ; 95^{\circ} \mathrm{C}\right)$ have been described by Dhuique-Mayer et al. (2007). The present profile of 328 carotenoids in OFSP flour showed that there were very few qualitative differences in the 329 chromatogram of samples immediately before or after drying, or after storage for 4 months.

\section{Kinetics of individual carotenoid degradation during storage}

331 Kinetics of carotenoid loss per variety are presented in Table 4. For trans $\beta$-carotene and $\beta$ 332 carotene 5,6-epoxide, the coefficients of correlation with storage time were generally higher 333 than $\mathrm{R}=-0.95$. MGCL01 variety fitted better first order kinetics whilst Resisto fitted equally 334 zero and first order kinetics and this has not been reported previously. Instead, it has been 335 shown that dried food fitted first order kinetics degradation during storage (Hidalgo \& 336 Brandolini, 2008; Koca et al., 2007). Nevertheless, working on pure $\beta$-carotene powder, 337 Minguez-Mosquera \& Jaren-Galan (1995) demonstrated that degradation followed zero-order 338 kinetics in an organic anhydrous medium while in an aqueous medium it followed first-order 339 kinetics. Zero order reactions are found when the substrate is in excess. Because Resisto had 340 twice as much trans- $\beta$-carotene as MGCL01 this could possibly explain why the zero order 341 reaction also fitted Resisto. This indicates that the oxidant had no limitation on the substrate 342 which means that oxygen from the air could easily penetrate the product. There are a few 343 discrepancies between the two models because in order zero Resisto degradation was faster 
344 than MGCL01 and order one the opposite. Because coefficients of correlation were higher in 345 first order, particularly on MGCL01, the first order was considered. First order rates of 346 degradation were $0.0171 \mathrm{day}^{-1}$ for trans- $\beta$-carotene on Resisto and 0.0251 day $^{-1}$ on MGCL01.

347 The rate of degradation of $\beta$-carotene 5,6 epoxide was slightly faster than that of trans- $\beta$ 348 carotene (0.0249 and 0.0315 day $^{-1}$ on Resisto and MGCL01 respectively) and this was in 349 accordance with recent work by Bechoff et al. (2010b).

351 Isomers of $\beta$-carotene, 13-cis- and 9-cis-, degraded following first order kinetics however 352 with coefficients of correlation with storage time lower than trans- $\beta$-carotene and 5,6 epoxide$353 \beta$-carotene $(\mathrm{R} \sim 0.80)$. Rate constants of 13-cis- and 9-cis isomers in Resisto and MGCL01 354 being $0.0080 ; 0.0102$ and $0.0115 ; 0.0190$ day $^{-1}$ respectively were less than that of trans- $\beta$ 355 carotene (0.0171 and $\left.0.0251 \mathrm{day}^{-1}\right)$. This observation is significant because, to our knowledge, 356 the rate of degradation of cis-isomers has not been widely reported in literature when working 357 on storage. A degradation of cis-isomers jointly with trans- $\beta$-carotene in solar-drying was 358 however reported by Bechoff et al. (2009); Kidmose et al. (2007); Mulokozi \& Svanberg 359 (2003) working on sweet potato drying. In summary, these results showed that the 360 concentration of all the carotenoids was proportionally reduced in storage. 361

\section{CONCLUSION}

363 Compared to the earlier study carried out on-research station in Uganda (Bechoff et al. 364 2010a), retentions of total carotenoids after on-farm drying in Mozambique were similar, 365 when considering the same type of dryers (tunnel or sun dryers). It was shown in both studies 366 that a higher level of technology (tunnel dryer) as compared with a lower level of technology 367 (open air sun drying on raised trays), did not necessarily lead to a higher carotenoid retention. 
369 The lack of difference in carotenoid retention between different chip sizes during storage is 370 also positive for farmers, because it means that they can limit their management costs because 371 traditional hand slicing of sweet potato was as good as the use of a mechanical chipper on the

372 retention of carotenoids. On the other hand, the effect of variety was significant in drying and 373 storage. These observations require investigation on more varieties as this was noted in the 374 research station based study (Bechoff et al. 2010a).

375

376 Total carotenoid losses during storage were high and these considered being slightly greater 377 than the losses determined on-station in Uganda (results after four month-storage). Higher 378 losses in the on-farm based study in Mozambique may be explained by higher temperatures 379 and lower relative humidity (Bechoff et al., 2010b) especially in the day. In order to meet a 380 significant part of daily nutritional requirements in provitamin A (100g corresponding to $381100 \%$ of RDA for children) (Bechoff et al., 2010a), chip samples should not be stored for 382 more than two months for MGCL and four months for Resisto. However Resisto chips should 383 preferably not be stored more than three months because of insect damage.

385 It is possible to do on-farm research and to get similar results to that obtained on-research 386 station. These findings are important when transferring technology from a research station, 387 which includes control over research-parameters, to the more realistic situation of the farm 388 where farmers themselves monitor the drying and storage of their crops.

\section{ACKNOWLEDGEMENTS}

391 We are grateful to Gomes Frederico Pedro and Timoteo Andrade for their technical assistance 392 and to Tiago Manuel Alifo, farmer, for the use of his field in Lualua, Mozambique. This 393 research was supported by the HarvestPlus Challenge Program Project "Reaching End Users 
394 with orange fleshed sweetpotatoes in Uganda and Mozambique”. The views expressed are 395 however those of the authors.

396

\section{REFERENCES}

398 Aguayo, V.M. \& Baker, S.K. (2005). Vitamin A deficiency and child survival in sub-Saharan 399 Africa: A reappraisal of challenges and opportunities. Food and Nutrition Bulletin, 26, 348400355.

401

402

AOAC (1984). Official methods of Analysis of the Association of Official Analytical 403 Chemists. The Association of Official Analytical Chemists, Inc. Arlington, VA. 404 405

Arya, S.S., Natesan, V., D.B. Parihar \& Vijayaraghavan, P.K. (1979). Stability of carotenoids 406 in dehydrated carrots. International Journal of Food Science and Technology, 14, 579-586. 407 sweet potato. Journal of Food Composition and Analysis, 21, 134-143.

412 Bechoff, A., Westby, A., Dufour, D., Dhuique-Mayer, C., Marouze, C., Owori, C., Menya, 413 G., Tomlins, K.I. (2007). Effect of drying and storage on the content of pro-vitamin A in 414 orange fleshed sweetpotato: sun radiations do not have significant impact. 10th Triennial 415 Symposium of the International Society for Tropical Root Crops - Africa Branch (ISTRC$416 \mathrm{AB})$, "Root and Tuber Crops for Poverty Alleviation through Science and Technology for 417 Sustainable Development", IIAM, Maputo, Mozambique, 8 to 12 October. 
419 Bechoff A., Dufour D., Dhuique-Mayer C., Marouzé C., Reynes, M. \& Westby A. (2009).

420 Effect of hot air, solar and sun-drying treatments on provitamin A retention of orange-fleshed 421 sweet potato. Journal of Food Engineering, 92, 164-171.

422

423 Bechoff, A. (2010). Investigating carotenoid loss after drying and storage of orange-fleshed 424 sweet potato. PhD dissertation. July 2010. Natural Resources Institute, University of 425 Greenwich, UK, 263pp.

426

427 Bechoff, A., Westby, A., Owori, C., Menya, G., Dhuique-Mayer, C., Dufour D. \& Tomlins K. 428 (2010a). Effect of drying and storage on the degradation of total carotenoids in orange-fleshed 429 sweetpotato cultivars. Journal of the Science of Food and Agriculture, 90, 622-629 430

431 Bechoff, A., Dhuique-Mayer, C., Dornier, M., Tomlins, K., Boulanger, R., Dufour, D. \& 432 Westby, A. (2010b). Relationship between the kinetics of $\beta$-carotene degradation and 433 norisoprenoid formation in the storage of dried sweet potato chips. Food Chemistry, 121, $434 \quad 348-357$.

435

436 Chavez, A.L., Sanchez, T., Ceballos, H., Rodriguez-Amaya D.B., Nestel, P., Tohme, J. \& 437 Ishitani, M. (2007). Retention of carotenoids in cassava roots submitted to different 438 processing methods. Journal of the Science of Food \& Agriculture, 87, 388-393.

440 Chen, J.P., Tai, C.Y. \& Chen, B.H. (2007). Effects of different drying treatments on the 441 stability of carotenoids in Taiwanese mango (Mangifera indica L.). Food Chemistry, 100, $442 \quad 1005-1010$. 
444 Desorby, S.A., Netto, F.M. \& Labuza, T.P. (1997). Comparison of spray-drying, drum-drying 445 and freeze-drying for $\beta$-carotene encapsulation and preservation. Journal of Food Science, 62 , $446 \quad 1158-1162$.

448 Dhuique-Mayer, C., Tbatou, M., Carail, M., Caris-Veyrat, C., Dornier, M. \& Amiot, M.J. 449 (2007). Thermal Degradation of Antioxidant Micronutrient in Citrus Juice and Newly Formed 450 Compounds. Journal of Agricultural and Food Chemistry, 55, 4209-4216.

452 Emenhiser, C., Watkins, R.H., Simunovic, N. Solomons, N., Bulux, J., Barrows, J. \& 453 Schwartz, S.J. (1999). Packaging preservation of $\beta$-carotene in sweet potato flakes using 454 flexible film and an oxygen absorber. Journal of Food Quality, 22, 63-73. 455

456 Haralampu, S.G. \& Karel, M. (1983). Kinetic models for moisture dependence of ascorbic 457 acid and $\beta$-carotene degradation in dehydrated sweet potato. Journal of Food Science, 48, $458 \quad 1872-1873$. 459

460 Hidalgo, A.H.\& Brandolini, A. (2008). Kinetics of carotenoid degradation during the storage 461 of einkorn (Triticum monococcum L. ssp. monococcum) and bread wheat (Triticum aestivum 462 L. ssp. aestivum) flours. Journal of Agriculture \& Food Chemistry 56, 11300-11305. 463

464 Kidmose, U., Christensen, L.P., Agili, S.M. \& Thilsted, S.H. (2007). Effect of home 465 preparation practices on the content of provitamin A carotenoids in coloured sweet potato 466 varieties (Ipomoea batatas Lam.) from Kenya. Innovative Food Science and Emerging 467 Technologies, 8, 399-406. 
469 Koca, N., Burdurlu, H.S. \& Karadeniz, F. (2007). Kinetics of colour changes in dehydrated 470 carrots. Journal of Food Engineering, 78, 449-455.

471

472 Kósambo L., Carey E.E., Misra A.K., Wilkes J. and Hagenimana, V. (1998) Influence of age, 473 farming site, and boiling on pro-vitamin A content in sweet potato (Ipomoea batatas (L.) 474 Lam.). Journal of Food Analysis, 11, 305-321. 475 476 Low, J.W., Arimond, M., Osman N.,6 Cunguara, B., Zano, F. \& Tschirley, D. (2007). A food477 based approach introducing orange-fleshed sweet potatoes increased vitamin A intake and 478 serum retinol concentrations in young children in rural Mozambique. Journal of Nutrition 479 Community and International Nutrition, 137, 1320-1327.

480

481 Mills, R.C. \& Hart, E.B. (1945). Studies of the stabilization of carotene in dehydrated feeds 482 and foods. Journal of Dairy Science, 28, 1-13 483

484 Minguez-Mosquera, M.I. \& Jaran-Galan, M. (1995). Kinetics of the decolouring of carotenoid 485 pigments. Journal of Agricultural and Food Chemistry, 67, 153-161.

486

487 Mulokozi, U. \& Svanberg, G. (2003). Effect of Traditional Open Sun-Drying and Solar 488 Cabinet Drying on Carotene Content and Vitamin A Activity of Green Leafy Vegetables. 489 Plant Foods for Human Nutrition, 58, 1-15.

490

491 Negi, P.S. \& Roy, S.K.(2000). Effect of Blanching and Drying Methods on $\beta$-Carotene, 492 Ascorbic acid and Chlorophyll Retention of Leafy Vegetables. Lebensmittel Wissenschaft und 493 Technologie, 33, 295-298. 
495 Rodriguez Amaya, D.B. \& Kimura, M. (2004) HarvestPlus handbook for carotenoid analysis. 496 HarvestPlus Technical monograph series 2. HarvestPlus handbook for carotenoid analysis. 497 (pp. 1-58) Washington DC, USA: HarvestPlus c/o International Food Policy Research 498 Institute. [Online] http://www.harvestplus.org/pdfs/tech02.pdf 499

500 Stephanovitch, A.F. \& Karel, M. (1982). Kinetics of $\beta$-carotene degradation at temperatures 501 typical of air drying of foods. Journal of Food Processing and Preservation, 6, 227-242. 502 503 Teow, C.C., Truong, V.D, McFeeters, R. F., Thompson, R.L., Pecota, K.V. \& Yencho, G.C. 504 (2007). Antioxidant activities, phenolic and $\beta$-carotene contents of sweet potato genotypes 505 with varying flesh colours. Food Chemistry, 103, 829-838.

506

507 Tomlins, K.I., Ndunguru, G., Kimenya, F., Ngendello, T., Rwiza, E., Amour, R., van 508 Oirschot, Q. \& Westby, A. (2007). On-farm evaluation of methods for storing fresh sweet 509 potato roots in East Africa. Tropical Science, 47, 197-210. 510

511 van Straaten L. (2006). World Vision Mozambique. Agricultural and natural resources 512 management project. DAP II. End of Project survey report for OVATA. 68pp.

513

514 Walter, W.M. \& Purcell, A.E. (1974). Lipid autoxidation in precooked dehydrated sweet 515 potato flakes stored in air. Journal of Agricultural and Food Chemistry, 22, 298-302.

517 Wang, J.\& Xi, Y.S. (2005). Drying characteristics and drying quality of carrot using a two518 stage microwave process. Journal of Food Engineering, 68, 505-511. 
520 Weather Underground Quelimane (2007). History for Quelimane August-December 2007.

521 [Internet document]

522 .http://www.wunderground.com/history/station/67283/2007/10/13/MonthlyHistory.html .

523 Accessed 28/04/2010.

524

525 Woolfe, J. A. (1992) Post harvest procedures: Sweet potato an untapped food source.

526 Cambridge, UK: Cambridge University Press. 643pp. 
Table 1: Total carotenoid losses after drying influenced by treatment (dryer, chipping) using MGCL01 and Resisto varieties

\begin{tabular}{|c|c|c|c|c|c|c|}
\hline Variety & Chipping & Dryer & $\begin{array}{c}\text { Dry } \\
\text { matter } \\
\text { content } \\
(\%)\end{array}$ & $\begin{array}{l}\text { Drying } \\
\text { time }^{*}(\mathrm{~h})\end{array}$ & $\begin{array}{c}\text { Total carotenoid } \\
\text { content }\left(\mu \mathrm{g} \cdot \mathrm{g}^{-1} \mathrm{db}\right)^{* *}\end{array}$ & $\begin{array}{l}\text { Total } \\
\text { carotenoid } \\
\text { loss }(\%)\end{array}$ \\
\hline \multirow{8}{*}{$\begin{array}{l}\text { MGCL } \\
01\end{array}$} & Fresh roots & & 35.4 & & $235.6(6.5) b c$ & - \\
\hline & \multirow{3}{*}{ Thin chips } & Tunnel & 93.9 & 25.5 & $210.2(5.0) \mathrm{a}$ & 10.8 \\
\hline & & Open & 92.1 & 23.8 & 224.2 (6.0) abc & 4.9 \\
\hline & & Shade & 89.9 & 26.5 & $238.0(6.2) b c$ & $-1.0 * * *$ \\
\hline & Thick chips & Open & 89.6 & 23.9 & 224.5 (1.9) abc & 4.7 \\
\hline & \multirow{3}{*}{ Slices } & Tunnel & 91.4 & 47.7 & $204.9(2.6) \mathrm{a}$ & 13.0 \\
\hline & & Open & 87.7 & 47.6 & $219.4(3.2) \mathrm{ab}$ & 6.9 \\
\hline & & Shade & 86.8 & 50.7 & $242.5(6.3) c$ & $-2.9 * * *$ \\
\hline \multirow{8}{*}{ Resisto } & Fresh roots & & 27.0 & & $434.4(0.7) \mathrm{e}$ & - \\
\hline & \multirow{3}{*}{ Thin chips } & Tunnel & 91.9 & 26.1 & $371.1(2.5) b c$ & 14.6 \\
\hline & & Open & 91.5 & 25.4 & $362.8(13.0) \mathrm{b}$ & 16.5 \\
\hline & & Shade & 89.9 & 50.7 & $401.0(8.3) \mathrm{cd}$ & 7.7 \\
\hline & Thick chips & Open & 91.0 & 62.3 & $327.7(2.8) \mathrm{a}$ & 24.6 \\
\hline & \multirow{3}{*}{ Slices } & Tunnel & 88.8 & 72.4 & $376.2(4.8) b c$ & 13.4 \\
\hline & & Open & 84.0 & 75.4 & $383.6(6.2) b c$ & 11.7 \\
\hline & & Shade & 78.3 & 75.5 & $418.0(1.5) \mathrm{de}$ & 3.8 \\
\hline
\end{tabular}

* Drying time includes days and nights of samples spent on dryers -average of two-drying trials.

** db: dry weight basis. Each value represents the mean (standard deviation) of two extractions for two-drying trials $\left(2^{2}\right)$. For each sweet potato variety, values followed by different letters are significantly different (ANOVA-Tukey test; $\mathrm{p}<0.05$ ). Total carotenoid content was measured using a Hewlett Packard 8452A spectrophotometer at an absorbance of 450nm.

***Negative values are not significantly different from values in fresh sweet potatoes

Average and variation on day/night temperature and humidity respectively were $22^{\circ} \mathrm{C}\left(12-33^{\circ} \mathrm{C}\right)$ and $65 \%(25$ $95 \%)$ in ambient conditions; $26^{\circ} \mathrm{C}\left(11-55^{\circ} \mathrm{C}\right)$ and $(63 \%(13-100 \%)$ inside the tunnel dryer. 
538 Table 2: Effect of dryer type on carotenoid loss:

539 ANOVA (main effects) - Factors: variety: (Resisto, MGCL01); dryer (open, tunnel, 540 shade); chipper (slices, thin chips); replication trial, and final dry matter (after drying) 541 as a covariate 542

\begin{tabular}{lll}
\hline Source & df & Mean square \\
\hline Variety & 1 & $4.800^{* *}$ \\
Dryer & $\mathbf{2}$ & $\mathbf{2 . 0 0 0 * *}$
\end{tabular}

Chipper $\quad 1 \quad 0.100$

$\begin{array}{ll}1 & 0.002\end{array}$

Final dry matter (covariate) $1 \quad 0.600^{*}$

Error $\quad 410.100$

$543 *$ Significant at $\mathrm{p}<0.05 ; * *$ Significant at $\mathrm{p}<0.01$ 544 

4 5

545 Table 3: Effect of chipper on carotenoid loss after open air sun drying:

546 ANOVA (main effects) - Factors: variety (Resisto, MGCL01); chipper (slices, thick 547 chips, thin chips); replication trial, and final dry matter as a covariate 548

\begin{tabular}{lcl}
\hline Source & df & Mean Square \\
\hline Variety & 1 & $11.000 * *$ \\
Chipper & $\mathbf{2}$ & $\mathbf{1 . 1 0 0 * *}$ \\
Trial & 1 & $<0.001$
\end{tabular}

549

Final dry matter (covariate) $1 \quad 2.900 * *$

$\begin{array}{lll}\text { Error } & 18 & 0.100\end{array}$

550 
551 Table 4: Kinetic parameters of zero order and first order carotenoid degradation in 552 Resisto and MGCL01 slices stored for four months

553

\begin{tabular}{|c|c|c|c|c|c|c|c|c|c|}
\hline & \multirow[t]{2}{*}{$\begin{array}{l}\text { Reaction } \\
\text { Order }\end{array}$} & \multicolumn{2}{|c|}{ Trans- $\beta$-carotene } & \multicolumn{2}{|c|}{$\begin{array}{l}5,6 \text { epoxide- } \beta \text { - } \\
\text { carotene }\end{array}$} & \multicolumn{2}{|c|}{13 -cis- $\beta$-carotene } & \multicolumn{2}{|c|}{ 9-cis- $\beta$-carotene } \\
\hline & & $\mathrm{k}\left(\mathrm{day}^{-1}\right)$ & $\mathrm{R}$ & $\mathrm{k}\left(\mathrm{day}^{-1}\right)$ & $\mathrm{R}$ & $\mathrm{k}\left(\mathrm{day}^{-1}\right)$ & $\mathrm{R}$ & $\mathrm{k}\left(\mathrm{day}^{-1}\right)$ & $\mathrm{R}$ \\
\hline \multirow{2}{*}{ Resisto } & 0 & $\begin{array}{c}2.7643 \\
(0.2500)\end{array}$ & -0.976 & $\begin{array}{c}0.1840 \\
(0.0131)\end{array}$ & -0.985 & $\begin{array}{c}0.0376 \\
(0.0054)\end{array}$ & -0.943 & $\begin{array}{c}0.0228 \\
(0.0046)\end{array}$ & -0.896 \\
\hline & 1 & $\begin{array}{c}0.0171 \\
(0.0010)\end{array}$ & -0.990 & $\begin{array}{c}0.0249 \\
(0.0025)\end{array}$ & -0.971 & $\begin{array}{c}0.0080 \\
(0.0009)\end{array}$ & -0.963 & $\begin{array}{c}0.0102 \\
(0.0012)\end{array}$ & -0.963 \\
\hline \multirow{2}{*}{$\begin{array}{c}\text { MGCL } \\
01\end{array}$} & 0 & $\begin{array}{c}1.5436 \\
(0.2648)\end{array}$ & -0.922 & $\begin{array}{c}0.0989 \\
(0.0144)\end{array}$ & -0.942 & $\begin{array}{c}0.0261 \\
(0.0081)\end{array}$ & -0.796 & $\begin{array}{c}0.0180 \\
(0.0057)\end{array}$ & -0.791 \\
\hline & 1 & $\begin{array}{c}0.0251 \\
(0.0028)\end{array}$ & -0.966 & $\begin{array}{c}0.0315 \\
(0.0035)\end{array}$ & -0.965 & $\begin{array}{c}0.0115 \\
(0.0033)\end{array}$ & -0.819 & $\begin{array}{c}0.0190 \\
(0.0039)\end{array}$ & -0.893 \\
\hline
\end{tabular}

554

Each value represents the mean (standard deviation) of two extractions

555

556

557

558

559 
560

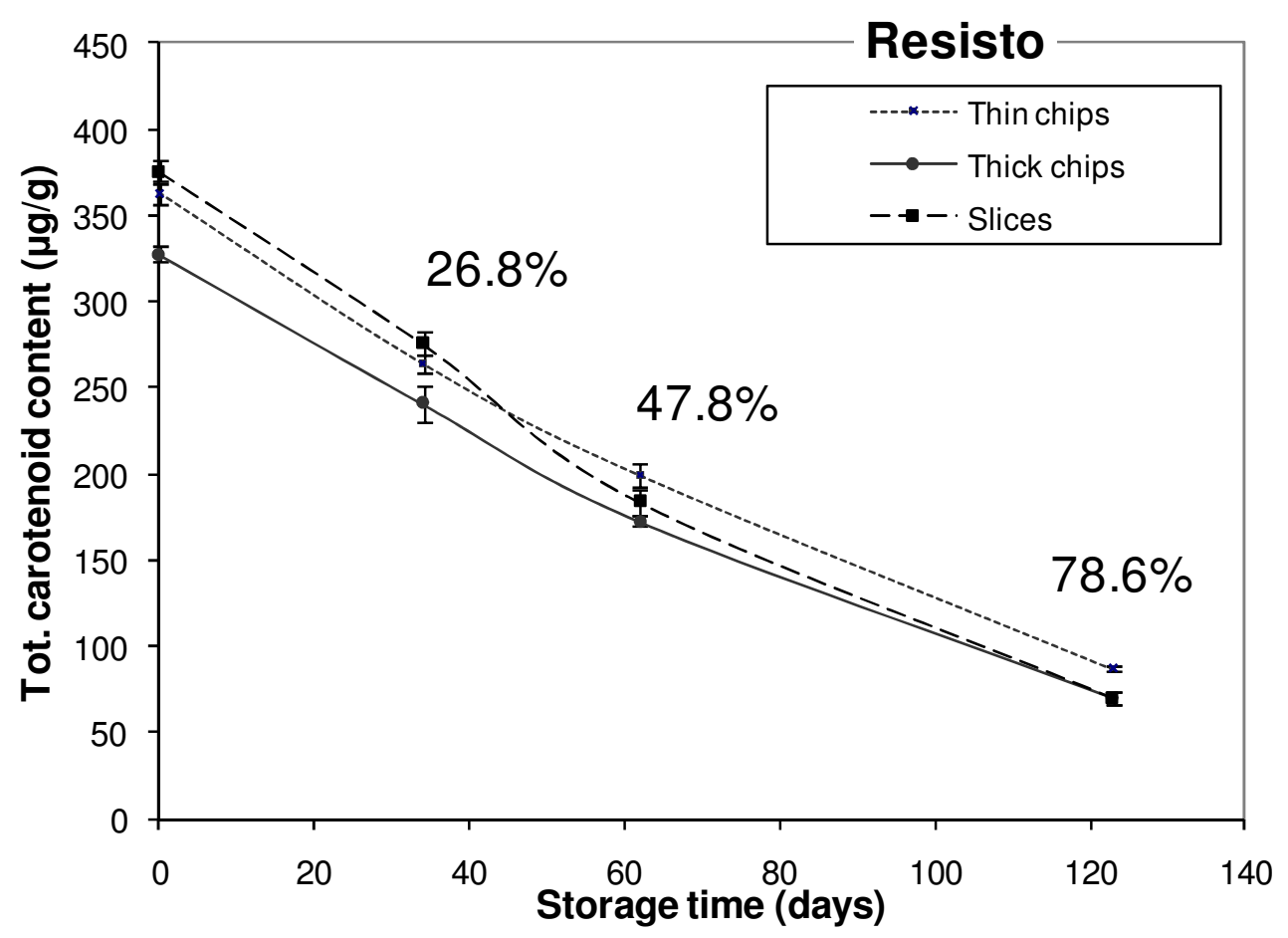

561

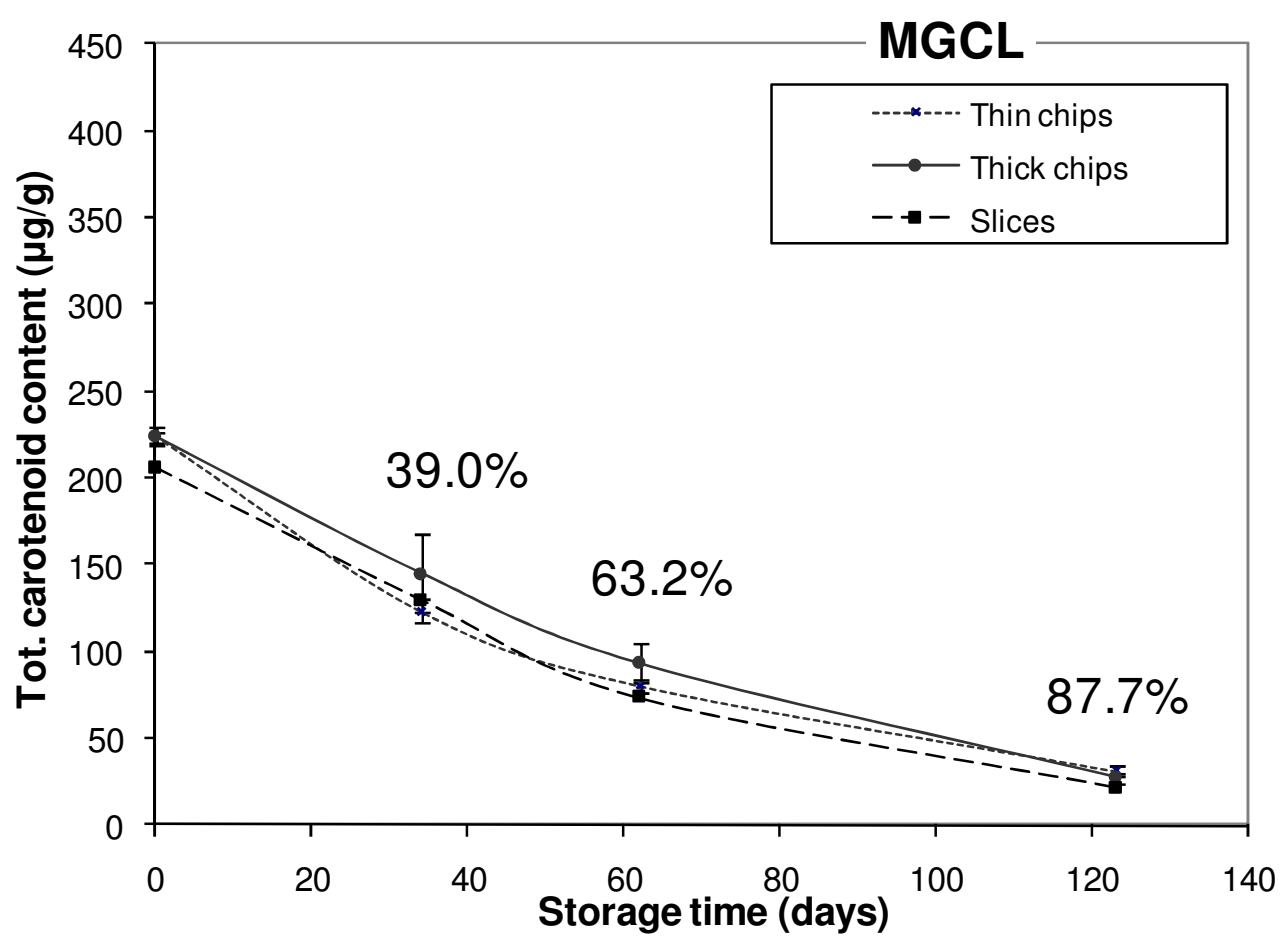

562

563

Figure 1: Kinetics of total carotenoid degradation during storage of Resisto and

564 MGCL01 varieties chipped to three different sizes. Mean of $2^{2}$ replicate; error bars refer to 565 standard error. 


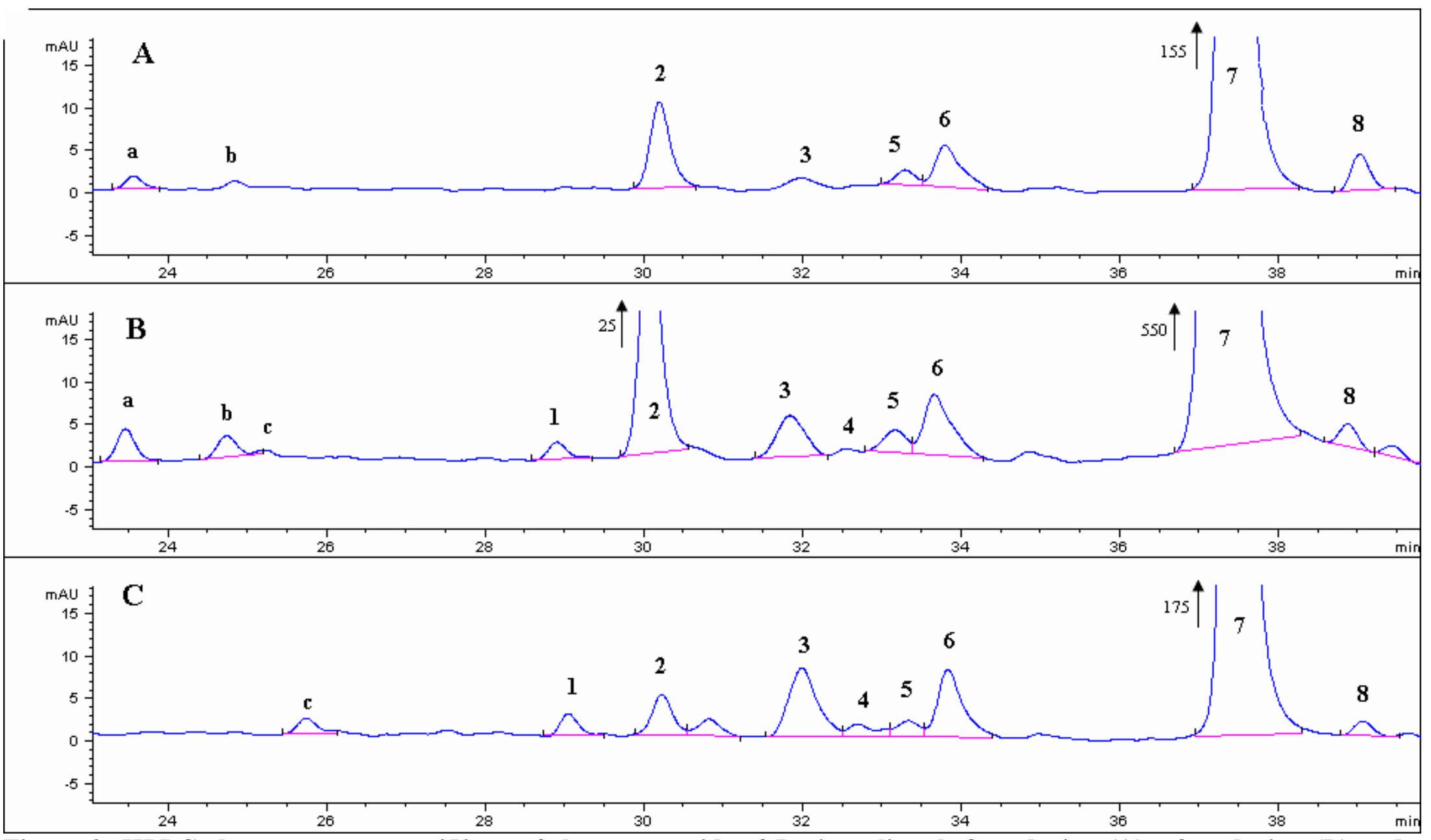

Figure 2: HPLC chromatograms at 450nm of the carotenoids of Resisto slices before drying (A), after drying (B) and after 120 days storage (C). a: Possibly $\beta$-carotene-5,6,5',6'-diepoxide (23 min.) (414; 440; 468nm); b: Possibly $\beta$-carotene-5,6,5',8'-diepoxide (24 min.) (400; 422; 450nm); c: unidentified (25 min.) (406; 424; 450nm); 1: Possibly 13-cis- $\beta$-carotene-5,6 epoxide (29min.) (main wavelengths: 416; 439; 476nm); 2 : Possibly $\beta$-carotene-5,6 epoxide (30min.) (422;446; 472nm); 3: Possibly $\beta$-carotene-5,8 epoxide (32min.) (406;428; 452nm); 4\&5: Unidentified; 6:13-cis $\beta$-carotene (34min.) (338;422;444; 472nm); 7: Alltrans- $\beta$-carotene $(37 \mathrm{~min}$.) $(\mathbf{4 5 2} ; 478 \mathrm{~nm}) ; 8$ : Possibly 9 cis- $\beta$-carotene $(39 \mathrm{~min}).(\mathbf{4 4 6} ; 472 \mathrm{~nm})$. The three graphs are not to the same scale because of differing dry matter contents (respectively $27 \%, 89 \%$ and $87 \%$ ). The graphs have been scaled to illustrate the minor peaks and therefore the larger peaks have been truncated. 


\section{On-farm evaluation of the impact of drying and storage on the}

2 carotenoid content of orange-fleshed sweet potato (Ipomea batata

3 Lam.)

\section{Running head: On-farm carotenoid loss in sweet potato chips}

5

6 Aurélie Bechoff ${ }^{1^{*}}$, Keith Tomlins ${ }^{1}$, Claudie Dhuique-Mayer ${ }^{2}$, Richard Dove ${ }^{3}$ and

7 Andrew Westby ${ }^{1}$

$8{ }^{I}$ Natural Resources Institute, University of Greenwich, Central Avenue, Chatham Maritime,

$9 \quad$ Kent ME4 4TB, United Kingdom.

$10 \quad{ }^{2}$ Centre International de Recherche Agronomique pour le Développement (CIRAD) UMR

11 Qualisud, TA 95B/16, 34398 Montpellier, France

$12{ }^{3}$ HarvestPlus Reaching End Users Project, World Vision, CP 517, Rua de Resistencia, 13 Quelimane, Mozambique

$14 *$ Correspondence to: Aurelie Bechoff, Natural Resources Institute (NRI), University of 15 Greenwich, Central Avenue, Chatham, Kent ME4 4TB, UK. Email: a.bechoff@gre.ac.uk 16

17 Abstract: Drying of orange-fleshed sweet potato was evaluated under African rural 18 conditions. Three locally-built dryers (open air-sun; tunnel and shade) were tested using 19 Resisto and MGCL01 varieties in Mozambique. Total carotenoid losses were low in all dryers 20 being $9.2 \%$ on average. After drying sweet potato chips were stored in a traditional way (jute 21 bags inside a mud house). Chip size (thin, thick chip or slice) had a significant effect on 22 drying $(\mathrm{p}<0.05)$ but not on storage; and variety had an effect on both. Total carotenoid losses 23 during storage were much higher being $83.7 \%$ on average, after four months, with main 24 individual carotenoids fitting a first order kinetics degradation. Globally carotenoid losses on25 farm or on-research station, were of similar level. 
26 Keywords: Ipomea batata (L.) Lam, carotenoids, storage, drying, on-farm, on-research.

27

\section{INTRODUCTION}

29 Mozambique is one of the poorest countries in the world, and additionally, one of the most 30 affected by vitamin A deficiency; $71 \%$ of the children under five are deficient (Aguayo \& 31 Baker, 2005). White-fleshed sweet potato (WFSP) is traditionally part of the Mozambican 32 diet, as a source of carbohydrate. An integrated agricultural and nutritional intervention 33 involving households with young children in rural areas of Mozambique has demonstrated 34 that regular consumption of orange-fleshed sweet potato (OFSP), rich in $\beta$-carotene, 35 significantly improved the vitamin A status of the children (Low et al., 2007). The marketing 36 and consumption of OFSP in Mozambique has increased as a result of initiatives by Centro 37 Internacional de la Papa (CIP) and Instituto de Investigação Agrária de Moçambique (IAAM), 38 and recent promotion programmes, such as the HarvestPlus Reaching End Users Project 39 (2006-2010). New ways of consuming OFSP in forms such as juice, bread and confectionary 40 products are being investigated in order to extend the availability and nutritional benefits 41 through both home consumption and trade. The availability of fresh sweet potato is seasonal 42 and storage of the fresh root beyond 3 months is difficult (Tomlins et al., 2007). Hence the 43 production of dried products could potentially extend the availability of sweet potato by up to 44 4-6 months. Sun-drying of sweet potato is a traditional processing practice in many 45 developing countries including a number of African countries (Woolfe, 1992). Although sun46 drying of sweet potato has been reported in Mozambique (Dove R., pers. comm.), reports 47 have been scarce. A World Vision survey for OVATA in Zambezia district, Mozambique 48 (van Straaten, 2006) indicated that about 35\% of households who grow sweet potato also 49 practiced drying of sweet potato. Sun-drying is a non-controlled technology and previous 50 studies on a range of commodities have demonstrated that the level of drying technology used 
51 has an impact on provitamin A carotenoid retention (Bechoff et al., 2009; Chen et al., 2007;

52 Desorby et al., 1997; Mulokozi \& Svanberg, 2003; Negi \& Roy, 2000). Sun-drying could

53 result in higher carotenoid losses than with other technologies, such as solar-drying

54 (Mulokozi \& Svanberg, 2003; Negi \& Roy, 2000). However recent publications (Bengtsson et

55 al., 2008; Bechoff et al., 2009; Bechoff et al., 2010a) have showed that carotenoid losses

56 from sweet potato chips during sun-drying were low and were similar to solar-drying. In

57 addition, it was demonstrated in an on-station study in Uganda (Bechoff et al., 2010a), that

58 losses of carotenoids were much more critical during storage for four months $(70.4 \%)$ than

59 during drying (9.0\%). Tomlins et al. (2007) argued that experimental results obtained on a

60 research station do not necessarily transfer to the farm situation because of variations in

61 farmer knowledge and the local environment. It was therefore important to verify the on-

62 station results in typical rural setting.

63

64 In order to better preserve provitamin A in sweet potato drying, there was a further need to 65 determine whether process variables influence carotenoid degradation and the rate of 66 degradation during storage. In an on-farm study, variables that can be straightforwardly 67 explored are sweet potato chip size and variety. In laboratory trials, chip size has been 68 reported to influence carotenoid degradation in sweet potato during sun-drying (Bechoff et 69 al., 2009) and the variety of sweet potato has also been reported to influence carotenoid 70 degradation (Bechoff et al., 2010a). Determination of kinetics of carotenoid degradation in 71 dried sweet potato during storage under laboratory conditions has been reported in literature 72 (Haralampu \& Karel, 1983; Stephanovitch \& Karel, 1982) but field studies measuring 73 carotenoid kinetics in dried food commodities such as sweet potato are scarce. The 74 determination of carotenoid degradation rate under on-farm conditions could bring a practical 
75 help to farmers and millers with the evaluation of dried OFSP shelf life that could potentially

76 lead to an improvement of the product quality.

77 The aim of the study was to evaluate simple and low-cost drying and storage for orange-

78 fleshed sweet potato (OFSP) on-farm. The main objective was to measure the level of 79 carotenoid loss after solar and sun drying and over a four-month storage period taking into 80 account the effect of variety and chipping. 81

\section{MATERIALS AND METHODS}

\section{Root samples}

84 Mature sweet potato roots (MGCL01 and Resisto varieties), about $80 \mathrm{~kg}$ per variety, were 85 purchased from farmers around Lualua, Zambézia Province, Mozambique (105 km from 86 Quelimane, the Province Capital). The exact root harvest age was not known. All roots were 87 processed within one to three days after harvest.

88 Dryers

89 Three dryers were constructed on a farm belonging to a subsistence farmer at Lualua. Apart 90 from the greenhouse clear plastic (Strawberry 3 seasons BPI-VISQUEEN®, UK thickness $91 \quad 150 \mu \mathrm{m}$ ), all building materials were obtained locally and constructed by local craftsmen. 92 Each of the dryers was mounted on a simple wooden structure that was fitted with straw mats. 93 - The tunnel dryer had similar dimensions to the on-research station dryer in Uganda (Bechoff 94 et al., 2010a). It had a total length of $9 \mathrm{~m}$ and a width of $1.5 \mathrm{~m}$. The collector (absorber) 95 occupied the first $3.5 \mathrm{~m}$ and was formed of an iron metal sheet. The rest of the dryer $(5.5 \mathrm{~m})$ 96 was used as drying area. The floor of the drying area was made of straw mats covered with 97 black plastic sheeting to insulate the structure. Clear greenhouse plastic covered the whole 
98 structure apart from the inlet and outlet allowing air flow and protected by mosquito net

$99\left(0.55 \mathrm{~m}^{2}\right.$ each $)$. The dryer had a $6^{\circ}$ slope.

100 - The open air dryer (exposed to direct sun) had a length of $6 \mathrm{~m}$ and a width of $1.5 \mathrm{~m}$ with a

101 height of $0.9 \mathrm{~m}$ and had a $6^{\circ}$ slope.

102 - The shade dryer was identical to the open air dryer and with the addition of a grass lined 103 roof. The roof was about $0.6 \mathrm{~m}$ larger and longer than the table in order to protect it from sun 104 light. The shade dryer was flat (i.e. without a $6^{\circ}$ slope) because of building constraints.

105 - Each dryer could fit 6 trays of $4 \mathrm{~kg}$ fresh sample each and surface area per tray was $1.03 \mathrm{~m}^{2}$.

106 The geographical position of the dryers was determined using GPS (GPS 60, GARMIN®).

107 Dryers were positioned facing north; this allowed maximum sun exposure in the southern 108 hemisphere. Temperature/humidity dataloggers (Tinytalk 2 Geminidatalogger, Chichester, 109 UK) were placed in the tunnel dryer and under the shade for ambient temperature 110 measurement.

111 Drying

112 Drying trials were carried out in duplicate on different days (one day and three days after 113 harvest). Roots were washed and spread on a black plastic under the shade for draining. Five 114 fresh roots per variety were collected for carotenoid analysis. On the drying day, unpeeled 115 roots were chipped using either a mechanical rotary disc chipper producing either thick and 116 thin chips, or were hand-sliced (traditional way). Size (thickness, width, length) of ten fresh 117 chips or slices was recorded using a digital calliper. Samples (4 kg) were weighed (Hanson 118 Electronic Chrome Effect Scale; $\pm 1 \mathrm{~g}$ ) after careful mixing (using a quartering technique). All 119 preparation operations were carried out in the shade to minimize losses in carotenoids. Sweet 120 potato samples were evenly spread on mosquito mesh trays (6 trays per dryer) at a density of $1213.9 \mathrm{~kg} \cdot \mathrm{m}^{-2}$. Loading time was recorded for each dryer. Samples were weighed and turned 122 frequently during drying. Samples were left overnight in the dryers because rain was unlikely 
123 at the time of the study. Under these field conditions, the end of drying was evaluated

124 subjectively by the presence of flour and a characteristic cracking noise when crushed in the

125 hand. The fresh samples of chips/slices per treatment with an initial weight of $4 \mathrm{~kg}$ (per

126 sample) reached a final weight of $1.5 \mathrm{~kg}$ for MGCL01 and $1.0 \mathrm{~kg}$ for Resisto after drying.

127 Collection of dried sweet potato chips for analysis and storage

128 A carefully mixed portion of dried chips/slices (about $200 \mathrm{~g}$ ) was collected in zip-polythene

129 bags and placed in a cooler bag before they were transported (within a couple of hours) to a 130 freezer $\left(-20^{\circ} \mathrm{C}\right)$ in Quelimane. The remainder of the chips/slices were used for the storage 131 study (at ambient temperature). Samples were stored in traditional bags made of jute and hung 132 inside a house constructed from mud in Lualua. In order to measure losses during storage, 133 sub-samples (200 g chips or slices per stored sample) were removed respectively after 1 134 month (31 days), 2 months (62 days) and 4 months (125 days) and placed in polythene bags in 135 a cooler bag and quickly transferred and stored in the freezer. The datalogger recording the 136 ambient temperature during storage was unfortunately lost, but it is estimated from records 137 taken nearby in Quelimane that the temperature in the mud house was on average $25{ }^{\circ} \mathrm{C}$ with 138 minimum/maximum temperatures of $20 / 31^{\circ} \mathrm{C}$ (Weather Underground Quelimane, 2007).

\section{Carotenoid analysis}

140 Chip samples in zip bags were stored at $-20^{\circ} \mathrm{C}$ for $1-6$ months before analysis because of 141 delays and the low sample throughput for this method. No significant carotenoid loss was 142 observed on chips in freezer in this interval $(\mathrm{p}<0.05)$ (Bechoff 2010). Samples were milled 143 into flour (particle sizes of less than $1 \mathrm{~mm}$ ) using a Laboratory mill 3600 (Perten Instruments, 144 Segeltorp, Sweden) and extracted in duplicate in a randomised order. Carotenoids were 145 identified and quantified using the method described by Bechoff et al. (2010b). The extraction 146 stage was adapted from Rodriguez-Amaya and Kimura (2004). A portion of the homogeneous 
1

3

4

5

6

7

8

9

147 representative sample (0.4-2.0 $\mathrm{g}$ of flour) was re-hydrated for $20 \mathrm{~min}$ in $10 \mathrm{ml}$ deionised 148 water, homogenised with $50 \mathrm{~mL}$ methanol:tetrahydrofuran (THF) (1:1) for 1 minute and 149 filtered. The homogenised extract was rinsed with methanol:THF (1:1) until there was no 150 yellow colour left in the filtrate. Partition between the aqueous phase and organic phase 151 containing the carotenoids was achieved by addition of petroleum ether $\left(\mathrm{PE}-40-60^{\circ} \mathrm{C}\right)$. The 152 PE phase was further washed with water, dried by addition of anhydrous sodium sulphate, 153 then filtered and made up to volume $(50 \mathrm{ml})$. For the determination of total carotenoid 154 content, absorbance was measured at $450 \mathrm{~nm}$ using a diode array Hewlett Packard 8452A 155 spectrophotometer. For the determination of individual carotenoids by HPLC, the carotenoid 156 extracts in PE were dried by flushing with nitrogen in a dry block system at $35^{\circ} \mathrm{C}$. The 157 extracts were dissolved in $1 \mathrm{ml}$ dichloromethane:MTBE (methyl tert-butyl ether): methanol 158 50:40:10. Reverse-phase high performance liquid chromatography using an Agilent 1100 159 system (Massy, France) was used following the method of Dhuique-Mayer et al. (2007). 160 Carotenoids were separated through a $\mathrm{C}_{30}$ reverse phase column $(250 \mathrm{x} 4.6 \mathrm{~mm}$ i.d.) packed 161 with $5 \mu \mathrm{m}$ YMC (EUROP GmbH, Germany) at a flow rate of $1 \mathrm{ml} . \mathrm{min}^{-1}$, a column 162 temperature at $25^{\circ} \mathrm{C}$ and an injection volume of $20 \mu \mathrm{l}$. Concentrations were determined by 163 comparison to a standard curve using pure $\beta$ - carotene (Extrasynthese, Genay, France). 164

165 Dry matter determination

166 Samples were collected for dry matter determination, before and after drying at the same time 167 as for carotenoids analysis. Determinations were made by drying triplicate $5 \mathrm{~g}$ samples at 105 $168{ }^{\circ} \mathrm{C}$ to constant weight (minimum 24h) (AOAC, 1984). 


\section{Statistical analyses and calculation of carotenoid degradation rates}

170 Normality of sample distribution was tested using Shapiro-Wilk and Kolmogorov Smirnov

171 tests $(\mathrm{p}<0.05)$. Analysis of variance (ANOVA) was carried out to determine whether there

172 were significant differences between samples with one up to four factors. A significant

173 difference between samples was determined by a Tukey test. Data were processed on SPSS

17415.00 (SPSS UK Ltd. Woking, Surrey, UK) for Windows software.

175

176 Linear regression (on Excel) was used to determine the rate of degradation $\mathrm{k}$ following the

177 formula $C=C_{0}-k t$ (zero order kinetics) or $\ln C=\ln C_{0}-k t$ (first order kinetics) where $\mathrm{C}_{0}$

178 is the total carotenoid content after drying $\left(\mu \mathrm{g} \cdot \mathrm{g}^{-1}\right) ; \mathrm{C}$ the total carotenoid content at storage

179 time $\mathrm{t}\left(\mu \mathrm{g} \cdot \mathrm{g}^{-1}\right) ; \mathrm{k}$ the rate constant $\left(\right.$ days $\left.^{-1}\right)$ and $\mathrm{t}$ the storage time (days).

180

181 RESULTS AND DISCUSSION

182

183 Effect of dryer on total carotenoid loss

184 Independently of the dryer or variety, average total carotenoid loss during drying was 9.2\%.

185 In all cases, levels of loss were less than 24.6\% (Table 1). Effect of different factors (new

Deleted: 17.6 186 chipper and traditional slicing) and three dryers (shade; sun; tunnel) on the two varieties was 187 evaluated on total carotenoid losses (Table 2). The type of dryer had a significant effect $188(\mathrm{p}<0.01)$ on total carotenoid loss. Because control over drying was limited in these field 189 conditions, dry matter was included as covariate in the analysis of variance from data 190 presented in Table 2. The three dryers gave significantly different results of loss: on average 191 there were $13.0 \%, 10.0 \%$ and $1.9 \%$ for the tunnel dryer; open air dryer and shade dryer 192 respectively (Table 1). Slight but significantly lower retention of total carotenoids in the 193 tunnel dryer compared to the open air dryer could be explained by the higher temperature 
194 during drying (up to $55^{\circ} \mathrm{C}$ whilst the ambient temperature did not go above $33^{\circ} \mathrm{C}$ ) (Table 1 ).

195 There was furthermore an issue with moisture evacuation from the product in the tunnel 196 dryer, which is illustrated by the maximum $100 \%$ relative humidity reached at night. This 197 may have resulted from a disadvantageous wind direction at this time of the year, blowing

198 East-West, whereas the tunnel was positioned North-South. As compared with the on-station 199 study (Bechoff et al., 2010a) using a similar but optimally oriented tunnel dryer, the on-farm 200 tunnel dryer showed some technical limitations in terms of air flow circulation. In terms of 201 carotenoid losses, the difference in the tunnel and open-air sun dryers (using chips of the same 202 size) was not significant $(9.0 \%$ for the tunnel and open-air sun dryers in the earlier on-station 203 study) (Bechoff et al., 2010a) and small (13\% and 10\% respectively working with thin chips 204 in this on-farm study). The tunnel dryer however protected against insects and rain. This type 205 of dryer was mostly designed for experimental use and, because its cost was estimated to be 206 ten times the cost of an open air dryer and five times that of a shade dryer, mainly due to 207 imported materials, it would not be a feasible proposition for Mozambican farmers to adopt. 208 The open air and shade dryer would be the dryers most suited to rural situation in 209 Mozambique because of their improved carotenoid retention, lower cost and availability of 210 most materials locally (on the farm or in the next village).

212 Complete protection from sun light and lower temperatures for shade-drying compared to 213 tunnel and open air sun dryers can explain the improved carotenoid retention from shade 214 drying. In this study, from an overall product quality perspective, the shade dryer worked well 215 with thin chips but was not well adapted to handcut slices (traditional way) because of longer 216 drying times leading to off-odours. Researchers, working with different commodities, have 217 reported conflicting results regarding carotenoid losses during shade-drying. Chavez et al. 218 (2007) reported that shaded-dried yellow cassava that contained carotenoids had improved 
219 carotenoid retention compared to sun-dried one, while Negi \& Roy (2000), working on leafy

220 vegetables, reported that higher carotenoid losses were obtained in shade and sun-drying as

221 opposed to solar (cabinet) drying. Theses inconsistencies in the literature could be the result

222 from different environmental conditions (temperature, humidity and wind) and different

223 product characteristics influencing carotenoid retention during drying.

224

225 Effect of chipping on total carotenoid loss after drying

226 Traditional slices, thick and thin chips had an average thickness of about $5.2 \mathrm{~mm}, 2.9 \mathrm{~mm}$ and

$2270.4 \mathrm{~mm}$ respectively. The effect of chipping treatment using three chipping treatment is 228 reported in open air drying for both MGCL01 and Resisto varieties (Table 1). There was no 229 difference between the thin chips and slices but drying thick chips resulted in significantly 230 higher loss than the other chipping methods, respectively $14.6 \%$ for thick chips and $10.7 \%$ for 231 thin chips; 9.3\% for traditional slices $(\mathrm{p}<0.01)$ (Table 3). Greater losses of total carotenoids in 232 thick chips compared to thin chips could be explained by inadequate chip size: with a small 233 surface area to volume ratio, thick chips may have evacuated moisture less efficiently and the 234 core of the chips may have been less protected during drying. Longer drying times were 235 associated with greater losses of carotenoids during drying of sweet potato (Bechoff et al. 236 2007). Bechoff et al. (2009) working on OFSP also reported that surface area of chip resulted 237 in differential carotenoid loss in sun-drying. In the drying of carrots Wang \& Xi (2005) 238 reported that $\beta$-carotene degradation increased with sample thickness and was also linked to 239 moisture content reached. In the case of slices, reasons might have been different. Greater 240 losses of total carotenoids in thick chips compared to slices could be explained by the greater 241 damage of tissues due to mechanical chipping as opposed to manual slicing. More 242 investigation is still needed to understand the relationships between chip surface/volume, 243 moisture evacuation and carotenoid loss during drying. 
244 Effect of variety on total carotenoid loss after drying

245 Sweet potato variety had a significant impact on total carotenoid loss $(\mathrm{p}<0.01)$. Resisto, with a 246 dry matter content of $27.0 \%$, lost more carotenoids (mean loss of $13.2 \%$ ) than MGCL01 with 247 a dry matter of $35.4 \%$ (mean loss of 5.2\%) (Table 1). A similar trend of higher dry matter 248 varieties being associated with lower carotenoid losses was reported by Bechoff et al. (2010a) 249 in on-station trials with six OFSP varieties. This difference between losses in Resisto and 250 MGCL01 varieties might result from difference between dry matter contents that would 251 influence the drying process.

\section{Effect of chipping on total carotenoid loss during storage}

254 Overall average losses in carotenoids from stored chips and slices after one month; two and 255 four months of storage are presented in Figure 1. No effect of chipping was reported when 256 analysing thin, thick chips and slices during storage (ANOVA; $\mathrm{p}<0.01$ ). The lack of 257 interaction between chipping and storage time confirmed that there was consistently no effect 258 of chipping throughout the storage period. Working on pure $\beta$-carotene encapsulated in 259 dextrose equivalent maltodextrin by three drying processes: spray, drum and freeze drying, 260 Desorby et al. (1997) found that larger particles obtained in drum drying had improved $\beta$ 261 carotene stability over storage when compared with the other processes. Mills \& Hart (1945) 262 working on dehydrated sweet potato also found that six month-stored flour had higher 263 carotene loss than sliced material at ambient temperature and concluded that sweet potato 264 should be stored in the way they are dehydrated rather than milled into flour. In the present 265 study, the lack of difference from chipping, however, did not agree with the results by 266 Desorby et al. (1997) and Mills \& Hart (1945), but it is believed that the difference in 267 retention observed in these previous studies is a result of the very different particle sizes of 268 samples tested (i.e. flour and slices) that may have resulted in differential porosity to air

Deleted: In this study, a new finding
was that there was a major varietal effect
associated to chipping ( $\mathrm{p}<0.01$ ). (Table
3); total carotenoid loss was on average
$17.6 \%$ on Resisto and 5.5\% on MGCL01.
Resisto chips produced by thick chipper
were sticky and took a long time to dry
(62.3h). The combined effect did not
exist when dry matter was included as
covariate in the analysis of variance
(Table 3). Therefore the higher sensitivity
of Resisto to the chipping type compared
to MGCL01 can be explained by its lower
initial dry matter content that requires
evacuating more moisture during drying
and is in agreement with Bechoff et al.
(2010a); Hagenimana et al. (1999). If
I


269 oxidation. This present study demonstrated that there was no effect of chip size in stored 270 samples. Oxidation is reported as the main factor responsible for carotenoid degradation 271 during storage of dried sweet potato (Emenhiser et al., 1999). Therefore the lack of 272 differences in this study is hypothesised to result from similar air oxygen diffusion through 273 the different chip/slice sizes (that did not differ as much in size as with flour and slices) of the 274 samples stored in jute bags.

275

276 Effect of variety on total carotenoid loss during storage

277 There was a significant effect of variety during storage of dried sweet potato $(\mathrm{p}<0.01)$. Resisto 278 with $26.8 \%, 47.8 \%, 78.6 \%$ loss after one month, two and four months of storage, had lower 279 total carotenoid losses than the MGCL01 variety with $39.0 \%, 63.2 \%, 87.7 \%$ respectively 280 (Figure 1). This could possibly result from differential composition in other constituents that 281 can enhance or delay carotenoid degradation: for instance, enhancers could be unsaturated 282 fatty acids that are mostly linoleic and linolenic acids in sweet potato (Walter \& Purcell, 283 1974) and were related to lipid peroxidation (Arya et al., 1979), and inhibitors of carotenoid 284 oxidation could be phenolic compounds. Phenolic content has been positively correlated to 285 antioxidant activity in various sweet potato varieties (Teow et al., 2007). More investigation 286 is required to understand varietal differences with regard to carotenoid retention.

\section{7}

288 Estimation of vitamin A activity in chips after drying and storage

289 Immediately after drying, average total carotenoid contents for Resisto and MGCL01 290 respectively were $355.6 \mu \mathrm{g} \cdot \mathrm{g}^{-1}$ and $218.2 \mu \mathrm{g} \cdot \mathrm{g}^{-1}$ on a dry weight basis. According to Bechoff 291 et al. (2010a), these values corresponded to an estimated vitamin A activity of 24617 and 15 292107 RE. $\mathrm{kg}^{-1}$ respectively and were largely beyond the recommended daily allowance for 293 children (4000 RE. $\mathrm{kg}^{-1}$ ). After a four month-storage, average total carotenoid contents for 
1

294 Resisto and MGCL01 were $73.4 \mu \mathrm{g} . \mathrm{g}^{-1}$ and $25.9 \mu \mathrm{g} \cdot \mathrm{g}^{-1}$ on a dry weight basis respectively.

295 These values corresponded to an estimated vitamin A activity of 5080 and 1796 RE. $\mathrm{kg}^{-1}$

296 respectively. After four month-storage the vitamin A activity is strongly reduced and only

297 Resisto variety meets the RDA. However because of other quality issues (i.e. presence of 298 insects) the recommended storage period should not exceed 3 months for Resisto. In order to 299 meet the RDA, the storage time for MGCL01 should not be over two months. These estimates 300 however do not take into account losses occurring during the further processing of dried sweet 301 potato into a form eaten by consumers. This should be the subject of another research study.

302 Identification of carotenoids before and after storage

303 The individual carotenoid compounds before drying, after drying and after 4 month-storage of 304 dried sweet potato were tentatively identified by HPLC (Figure 2). Resisto had the same 305 chromatographic profile as MGCL01. Therefore only the chromatograms for Resisto are 306 shown. The main compound is trans- $\beta$-carotene (peak 7) resolved at $37 \mathrm{~min}$. and representing $30784 \%$ of the total carotenoid concentration, both for Resisto and MGCL01 samples on average 308 (over dried and stored samples). Other peaks were minor compounds mostly degradation 309 products of all-trans- $\beta$-carotene and even present in fresh root samples in very small 310 quantities. The presence of $\beta$-carotene 5,6 epoxide has been reported by Kósambo et al. 311 (1998) in fresh sweet potato roots. On average (for dried and stored sliced Resisto variety) 312 percentages were the followings; $\beta$-carotene 5,6-epoxide (4.0\%), 5,6-epoxide (3.2\%) 9-cis $313(1.3 \%)$ and 13 -cis- $\beta$-carotene $(3.1 \%)$. Trans- $\beta$-carotene, $\beta$-carotene 5,6 -epoxide, 9 -cis and 13 314 cis- $\beta$-carotene were previously identified using the same HPLC system on a different sweet 315 potato variety (Bechoff et al., 2009). In spite of the degradation of $\beta$-carotene, no clear 316 increase of degradation products was readily observed using the HPLC technique. There are 317 minor differences between the chromatographic profiles of those samples, fresh (Figure 2A) 318 or dried (Figure 2B) or dried and subsequently stored (Figure 2C): peaks a (possibly $\beta$ - 
319 carotene-5,6,5',6'-diepoxide); b (possibly $\beta$-carotene-5,6,5',8'-diepoxide) were found in fresh

320 roots, peaks a, b and c (25 min.unidentified) were found in dried chips but peak c was only 321 detected after four months of storage. Peak 2 ( $\beta$-carotene 5,6 epoxide) was not affected by

322 drying but was sharply reduced during storage. On the other hand, peaks 3 ( $\beta$-carotene 5,8 323 epoxide) and 6 (13-cis $\beta$-carotene) decreased at a lower rate during storage. Storage affected 324 more the chromatographic profile of carotenoids than drying did. Harsher conditions of 325 processing may be necessary to induce more differences in the carotenoid profile. In contrast 326 to this study, significant differences in the chromatographic profile of fresh and heated citrus 327 juices $\left(5 \mathrm{~h} ; 95^{\circ} \mathrm{C}\right)$ have been described by Dhuique-Mayer et al. (2007). The present profile of 328 carotenoids in OFSP flour showed that there were very few qualitative differences in the 329 chromatogram of samples immediately before or after drying, or after storage for 4 months.

330 Kinetics of individual carotenoid degradation during storage

331 Kinetics of carotenoid loss per variety are presented in Table 4. For trans $\beta$-carotene and $\beta$ 332 carotene 5,6-epoxide, the coefficients of correlation with storage time were generally higher 333 than $\mathrm{R}=-0.95$. MGCL01 variety fitted better first order kinetics whilst Resisto fitted equally 334 zero and first order kinetics and this has not been reported previously. Instead, it has been 335 shown that dried food fitted first order kinetics degradation during storage (Hidalgo \& 336 Brandolini, 2008; Koca et al., 2007). Nevertheless, working on pure $\beta$-carotene powder, 337 Minguez-Mosquera \& Jaren-Galan (1995) demonstrated that degradation followed zero-order 338 kinetics in an organic anhydrous medium while in an aqueous medium it followed first-order 339 kinetics. Zero order reactions are found when the substrate is in excess. Because Resisto had 340 twice as much trans- $\beta$-carotene as MGCL01 this could possibly explain why the zero order 341 reaction also fitted Resisto. This indicates that the oxidant had no limitation on the substrate 342 which means that oxygen from the air could easily penetrate the product. There are a few 343 discrepancies between the two models because in order zero Resisto degradation was faster 
344 than MGCL01 and order one the opposite. Because coefficients of correlation were higher in 345 first order, particularly on MGCL01, the first order was considered. First order rates of 346 degradation were 0.0171 day $^{-1}$ for trans- $\beta$-carotene on Resisto and 0.0251 day ${ }^{-1}$ on MGCL01. 347 The rate of degradation of $\beta$-carotene 5,6 epoxide was slightly faster than that of trans- $\beta$ 348 carotene (0.0249 and 0.0315 day $^{-1}$ on Resisto and MGCL01 respectively) and this was in 349 accordance with recent work by Bechoff et al. (2010b).

351 Isomers of $\beta$-carotene, 13-cis- and 9-cis-, degraded following first order kinetics however 352 with coefficients of correlation with storage time lower than trans- $\beta$-carotene and 5,6 epoxide$353 \beta$-carotene $(\mathrm{R} \sim 0.80)$. Rate constants of 13-cis- and 9-cis isomers in Resisto and MGCL01 354 being $0.0080 ; 0.0102$ and $0.0115 ; 0.0190$ day $^{-1}$ respectively were less than that of trans- $\beta$ 355 carotene $\left(0.0171\right.$ and $\left.0.0251 \mathrm{day}^{-1}\right)$. This observation is significant because, to our knowledge, 356 the rate of degradation of cis-isomers has not been widely reported in literature when working 357 on storage. A degradation of cis-isomers jointly with trans- $\beta$-carotene in solar-drying was 358 however reported by Bechoff et al. (2009); Kidmose et al. (2007); Mulokozi \& Svanberg 359 (2003) working on sweet potato drying. In summary, these results showed that the 360 concentration of all the carotenoids was proportionally reduced in storage. 361 362 CONCLUSION

363 Compared to the earlier study carried out on-research station in Uganda (Bechoff et al. 364 2010a), retentions of total carotenoids after on-farm drying in Mozambique were similar, 365 when considering the same type of dryers (tunnel or sun dryers). It was shown in both studies 366 that a higher level of technology (tunnel dryer) as compared with a lower level of technology 367 (open air sun drying on raised trays), did not necessarily lead to a higher carotenoid retention. 
369 The lack of difference in carotenoid retention between different chip sizes during storage is

370 also positive for farmers, because it means that they can limit their management costs because

371 traditional hand slicing of sweet potato was as good as the use of a mechanical chipper on the

372 retention of carotenoids. On the other hand, the effect of variety was significant in drying and

373 storage. These observations require investigation on more varieties as this was noted in the

374 research station based study (Bechoff et al. 2010a).

376 Total carotenoid losses during storage were high and these considered being slightly greater 377 than the losses determined on-station in Uganda (results after four month-storage). Higher 378 losses in the on-farm based study in Mozambique may be explained by higher temperatures 379 and lower relative humidity (Bechoff et al., 2010b) especially in the day. In order to meet a 380 significant part of daily nutritional requirements in provitamin A (100g corresponding to 381 100\% of RDA for children) (Bechoff et al., 2010a), chip samples should not be stored for 382 more than two months for MGCL and four months for Resisto. However Resisto chips should 383 preferably not be stored more than three months because of insect damage.

385 It is possible to do on-farm research and to get similar results to that obtained on-research 386 station. These findings are important when transferring technology from a research station, 387 which includes control over research-parameters, to the more realistic situation of the farm 388 where farmers themselves monitor the drying and storage of their crops.

\section{ACKNOWLEDGEMENTS}

391 We are grateful to Gomes Frederico Pedro and Timoteo Andrade for their technical assistance 392 and to Tiago Manuel Alifo, farmer, for the use of his field in Lualua, Mozambique. This 393 research was supported by the HarvestPlus Challenge Program Project "Reaching End Users 


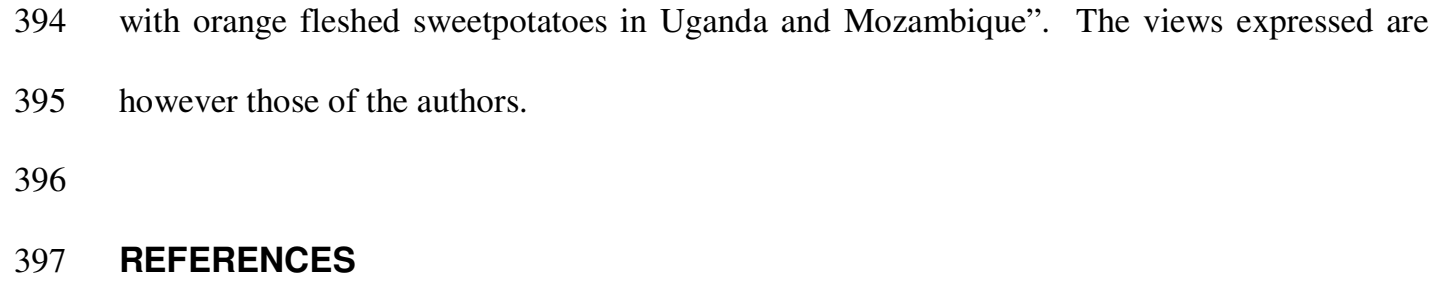

398 Aguayo, V.M. \& Baker, S.K. (2005). Vitamin A deficiency and child survival in sub-Saharan 399 Africa: A reappraisal of challenges and opportunities. Food and Nutrition Bulletin, 26, 348400355.

401

402 AOAC (1984). Official methods of Analysis of the Association of Official Analytical 403 Chemists. The Association of Official Analytical Chemists, Inc. Arlington, VA. 404 405 Arya, S.S., Natesan, V., D.B. Parihar \& Vijayaraghavan, P.K. (1979). Stability of carotenoids 406 in dehydrated carrots. International Journal of Food Science and Technology, 14, 579-586. 409 various traditional processing methods on the all-trans- $\beta$-carotene content of orange-fleshed 410 sweet potato. Journal of Food Composition and Analysis, 21, 134-143.

412 Bechoff, A., Westby, A., Dufour, D., Dhuique-Mayer, C., Marouze, C., Owori, C., Menya, 413 G., Tomlins, K.I. (2007). Effect of drying and storage on the content of pro-vitamin A in 414 orange fleshed sweetpotato: sun radiations do not have significant impact. 10th Triennial 415 Symposium of the International Society for Tropical Root Crops - Africa Branch (ISTRC$416 \mathrm{AB})$, "Root and Tuber Crops for Poverty Alleviation through Science and Technology for 417 Sustainable Development", IIAM, Maputo, Mozambique, 8 to 12 October. 
419 Bechoff A., Dufour D., Dhuique-Mayer C., Marouzé C., Reynes, M. \& Westby A. (2009).

420 Effect of hot air, solar and sun-drying treatments on provitamin A retention of orange-fleshed

421 sweet potato. Journal of Food Engineering, 92, 164-171.

422

423 Bechoff, A. (2010). Investigating carotenoid loss after drying and storage of orange-fleshed

424 sweet potato. PhD dissertation. July 2010. Natural Resources Institute, University of

425 Greenwich, UK, 263pp.

426

427 Bechoff, A., Westby, A., Owori, C., Menya, G., Dhuique-Mayer, C., Dufour D. \& Tomlins K.

428 (2010a). Effect of drying and storage on the degradation of total carotenoids in orange-fleshed

429 sweetpotato cultivars. Journal of the Science of Food and Agriculture, 90, 622-629

430

431 Bechoff, A., Dhuique-Mayer, C., Dornier, M., Tomlins, K., Boulanger, R., Dufour, D. \& 432 Westby, A. (2010b). Relationship between the kinetics of $\beta$-carotene degradation and 433 norisoprenoid formation in the storage of dried sweet potato chips. Food Chemistry, 121, $434 \quad 348-357$.

435

436 Chavez, A.L., Sanchez, T., Ceballos, H., Rodriguez-Amaya D.B., Nestel, P., Tohme, J. \& 437 Ishitani, M. (2007). Retention of carotenoids in cassava roots submitted to different 438 processing methods. Journal of the Science of Food \& Agriculture, 87, 388-393. 439

440 Chen, J.P., Tai, C.Y. \& Chen, B.H. (2007). Effects of different drying treatments on the 441 stability of carotenoids in Taiwanese mango (Mangifera indica L.). Food Chemistry, 100, $442 \quad 1005-1010$. 
444 Desorby, S.A., Netto, F.M. \& Labuza, T.P. (1997). Comparison of spray-drying, drum-drying 445 and freeze-drying for $\beta$-carotene encapsulation and preservation. Journal of Food Science, 62 , $446 \quad 1158-1162$.

447

448 Dhuique-Mayer, C., Tbatou, M., Carail, M., Caris-Veyrat, C., Dornier, M. \& Amiot, M.J. 449 (2007). Thermal Degradation of Antioxidant Micronutrient in Citrus Juice and Newly Formed 450 Compounds. Journal of Agricultural and Food Chemistry, 55, 4209-4216.

451

452 Emenhiser, C., Watkins, R.H., Simunovic, N. Solomons, N., Bulux, J., Barrows, J. \& 453 Schwartz, S.J. (1999). Packaging preservation of $\beta$-carotene in sweet potato flakes using 454 flexible film and an oxygen absorber. Journal of Food Quality, 22, 63-73.

456 Haralampu, S.G. \& Karel, M. (1983). Kinetic models for moisture dependence of ascorbic 457 acid and $\beta$-carotene degradation in dehydrated sweet potato. Journal of Food Science, 48, $458 \quad 1872-1873$.

\section{9}

460 Hidalgo, A.H.\& Brandolini, A. (2008). Kinetics of carotenoid degradation during the storage 461 of einkorn (Triticum monococcum L. ssp. monococcum) and bread wheat (Triticum aestivum 462 L. ssp. aestivum) flours. Journal of Agriculture \& Food Chemistry 56, 11300-11305. 463 464 Kidmose, U., Christensen, L.P., Agili, S.M. \& Thilsted, S.H. (2007). Effect of home 465 preparation practices on the content of provitamin A carotenoids in coloured sweet potato 466 varieties (Ipomoea batatas Lam.) from Kenya. Innovative Food Science and Emerging 467 Technologies, 8, 399-406.

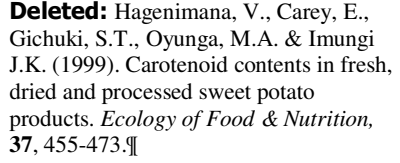
dried and processed sweet potato products. Ecology of Food \& Nutrition, 37, 455-473.II 
469 Koca, N., Burdurlu, H.S. \& Karadeniz, F. (2007). Kinetics of colour changes in dehydrated

470 carrots. Journal of Food Engineering, 78, 449-455.

471

472 Kósambo L., Carey E.E., Misra A.K., Wilkes J. and Hagenimana, V. (1998) Influence of age, 473 farming site, and boiling on pro-vitamin A content in sweet potato (Ipomoea batatas (L.) 474 Lam.). Journal of Food Analysis, 11, 305-321.

475

476 Low, J.W., Arimond, M., Osman N.,6 Cunguara, B., Zano, F. \& Tschirley, D. (2007). A food477 based approach introducing orange-fleshed sweet potatoes increased vitamin A intake and 478 serum retinol concentrations in young children in rural Mozambique. Journal of Nutrition 479 Community and International Nutrition, 137, 1320-1327.

480

481 Mills, R.C. \& Hart, E.B. (1945). Studies of the stabilization of carotene in dehydrated feeds 482 and foods. Journal of Dairy Science, 28, 1-13 483

484 Minguez-Mosquera, M.I. \& Jaran-Galan, M. (1995). Kinetics of the decolouring of carotenoid 485 pigments. Journal of Agricultural and Food Chemistry, 67, 153-161.

486

487 Mulokozi, U. \& Svanberg, G. (2003). Effect of Traditional Open Sun-Drying and Solar 488 Cabinet Drying on Carotene Content and Vitamin A Activity of Green Leafy Vegetables. 489 Plant Foods for Human Nutrition, 58, 1-15.

490

491 Negi, P.S. \& Roy, S.K.(2000). Effect of Blanching and Drying Methods on $\beta$-Carotene, 492 Ascorbic acid and Chlorophyll Retention of Leafy Vegetables. Lebensmittel Wissenschaft und 493 Technologie, 33, 295-298. 


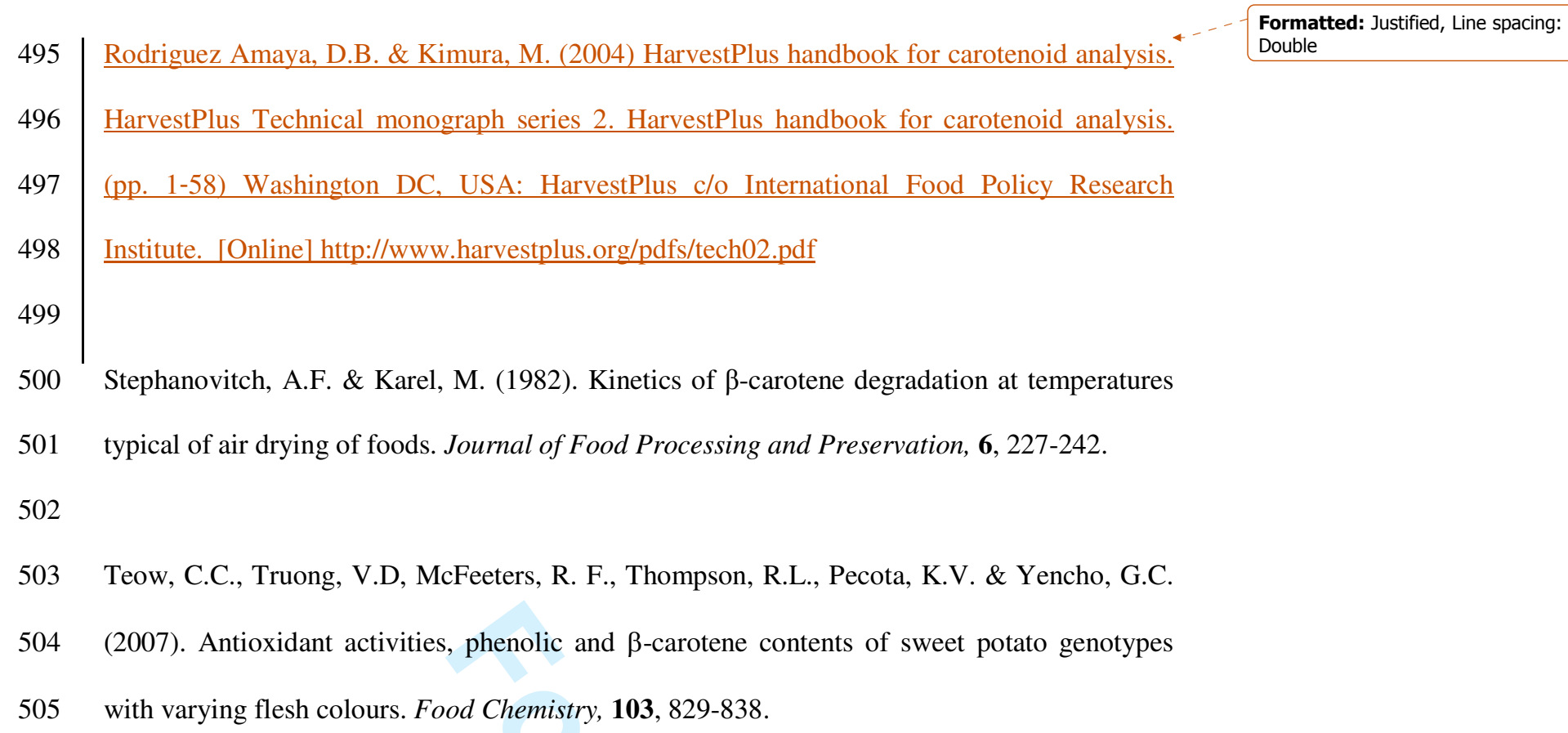


520 Weather Underground Quelimane (2007). History for Quelimane August-December 2007.

$521 \quad$ [Internet document]

522 .http://www.wunderground.com/history/station/67283/2007/10/13/MonthlyHistory.html .

523 Accessed 28/04/2010.

524

525 Woolfe, J. A. (1992) Post harvest procedures: Sweet potato an untapped food source.

526 Cambridge, UK: Cambridge University Press. 643pp.

15

16

17

18

19

20

21 
538 Table 2: Effect of dryer type on carotenoid loss:

539 ANOVA (main effects) - Factors: variety: (Resisto, MGCL01); dryer (open, tunnel, 540 shade); chipper (slices, thin chips); replication trial, and final dry matter (after drying) 541 as a covariate

542

\begin{tabular}{|c|c|c|}
\hline Source & $\mathrm{df}$ & Mean square \\
\hline Variety & 1 & $4.800 * *$ \\
\hline
\end{tabular}

Chipper

10.100

Trial

$1 \underline{0.002}$

Final dry matter (covariate)

$10.600 *$

Error

$$
41 \underline{0.100}
$$
48
Deleted: Analysis of variance

Deleted: for total carotenoid content (on a dry weight basis)

Deleted: using

Deleted: (2)

Deleted: (3)

Deleted: (2)

Deleted: (2)

Formatted Table

Deleted: $216268.71^{* *}$

Formatted: Font color: Auto

Formatted: Font: Bold

Deleted: 1735.01**

Formatted: Font: Bold, Font color:

Auto

Deleted: 1

Deleted: 0

Deleted: 167.35

Formatted: Font color: Auto

Deleted: 54.19

Formatted: Font color: Auto Deleted: D

Deleted: $1375.83^{* *}$

Formatted: Font color: Auto

Deleted: 122.72

Formatted: Font color: Auto 
1

2

3

4

5

6

7

8

9

10

11

12

13
545 Table 3: Effect of chipper on carotenoid loss after open air sun drying:

546 ANOVA (main effects) - Factors: variety (Resisto, MGCL01); chipper (slices, thick 547 chips, thin chips); replication trial, and final dry matter as a covariate

548

\begin{tabular}{lll}
$\underline{\text { Source }}$ & $\underline{\mathrm{df}}$ & Mean Square \\
\hline$\underline{\text { Variety }}$ & $\underline{1}$ & $\underline{11.000^{* *}}$
\end{tabular}

Chipper

$2 . \underline{1.100 * *}$

$\underline{\text { Trial }}$

$1 \leq 0.001$

Final dry matter (covariate) $\quad 1 \quad \underline{2.900 * *}$

Error $\quad \underline{18 \quad \underline{0.100}}$

\section{$\underline{23}$}

Deleted:

Deleted: Analysis of variance

Deleted: for total carotenoid content (on a dry weight basis) after open air sun drying using

Deleted:

Deleted: (2); chipper (3); replication trial (2) II

Formatted Table

Formatted: Font: Bold

Formatted: Font: Bold

Formatted: Font: (Default) Times

New Roman, (Asian) Times New

Roman, 12 pt, Complex Script Font:

Times New Roman, 12 pt

Formatted: Font: (Default) Times New Roman, 12 pt, Complex Script Font: Times New Roman, 12 pt

Deleted: $\mathbb{\|}$

Dry matter (covariate): ... [1]

Deleted: ...........Page Break .......... 
552 Table 4: Kinetic parameters of zero order and first order carotenoid degradation in

553 Resisto and MGCL01 slices stored for four months

\begin{tabular}{|c|c|c|c|c|c|c|c|c|c|}
\hline & \multirow[t]{2}{*}{$\begin{array}{c}\text { Reaction } \\
\text { Order }\end{array}$} & \multicolumn{2}{|c|}{ Trans- $\beta$-carotene } & \multicolumn{2}{|c|}{$\begin{array}{l}5,6 \text { epoxide- } \beta \text { - } \\
\text { carotene }\end{array}$} & \multicolumn{2}{|c|}{13 -cis- $\beta$-carotene } & \multicolumn{2}{|c|}{ 9-cis- $\beta$-carotene } \\
\hline & & $\mathrm{k}\left(\right.$ day $\left.^{-1}\right)$ & $\mathrm{R}$ & $\mathrm{k}\left(\right.$ day $\left.^{-1}\right)$ & $\mathrm{R}$ & $\mathrm{k}\left(\mathrm{day}^{-1}\right)$ & $\mathrm{R}$ & $\mathrm{k}\left(\mathrm{day}^{-1}\right)$ & $\mathrm{R}$ \\
\hline \multirow[b]{2}{*}{ Resisto } & 0 & $\begin{array}{c}2.7643 \\
(0.2500)\end{array}$ & -0.976 & $\begin{array}{c}0.1840 \\
(0.0131)\end{array}$ & -0.985 & $\begin{array}{c}0.0376 \\
(0.0054)\end{array}$ & -0.943 & $\begin{array}{c}0.0228 \\
(0.0046)\end{array}$ & -0.896 \\
\hline & 1 & $\begin{array}{c}0.0171 \\
(0.0010)\end{array}$ & -0.990 & $\begin{array}{c}0.0249 \\
(0.0025)\end{array}$ & -0.971 & $\begin{array}{c}0.0080 \\
(0.0009)\end{array}$ & -0.963 & $\begin{array}{c}0.0102 \\
(0.0012)\end{array}$ & -0.963 \\
\hline \multirow{2}{*}{$\begin{array}{c}\text { MGCL } \\
01\end{array}$} & 0 & $\begin{array}{c}1.5436 \\
(0.2648)\end{array}$ & -0.922 & $\begin{array}{c}0.0989 \\
(0.0144)\end{array}$ & -0.942 & $\begin{array}{c}0.0261 \\
(0.0081)\end{array}$ & -0.796 & $\begin{array}{c}0.0180 \\
(0.0057)\end{array}$ & -0.791 \\
\hline & 1 & $\begin{array}{c}0.0251 \\
(0.0028)\end{array}$ & -0.966 & $\begin{array}{c}0.0315 \\
(0.0035)\end{array}$ & -0.965 & $\begin{array}{c}0.0115 \\
(0.0033)\end{array}$ & -0.819 & $\begin{array}{c}0.0190 \\
(0.0039)\end{array}$ & -0.893 \\
\hline
\end{tabular}

555 Each value represents the mean (standard deviation) of two extractions

556

557

558

559

560 

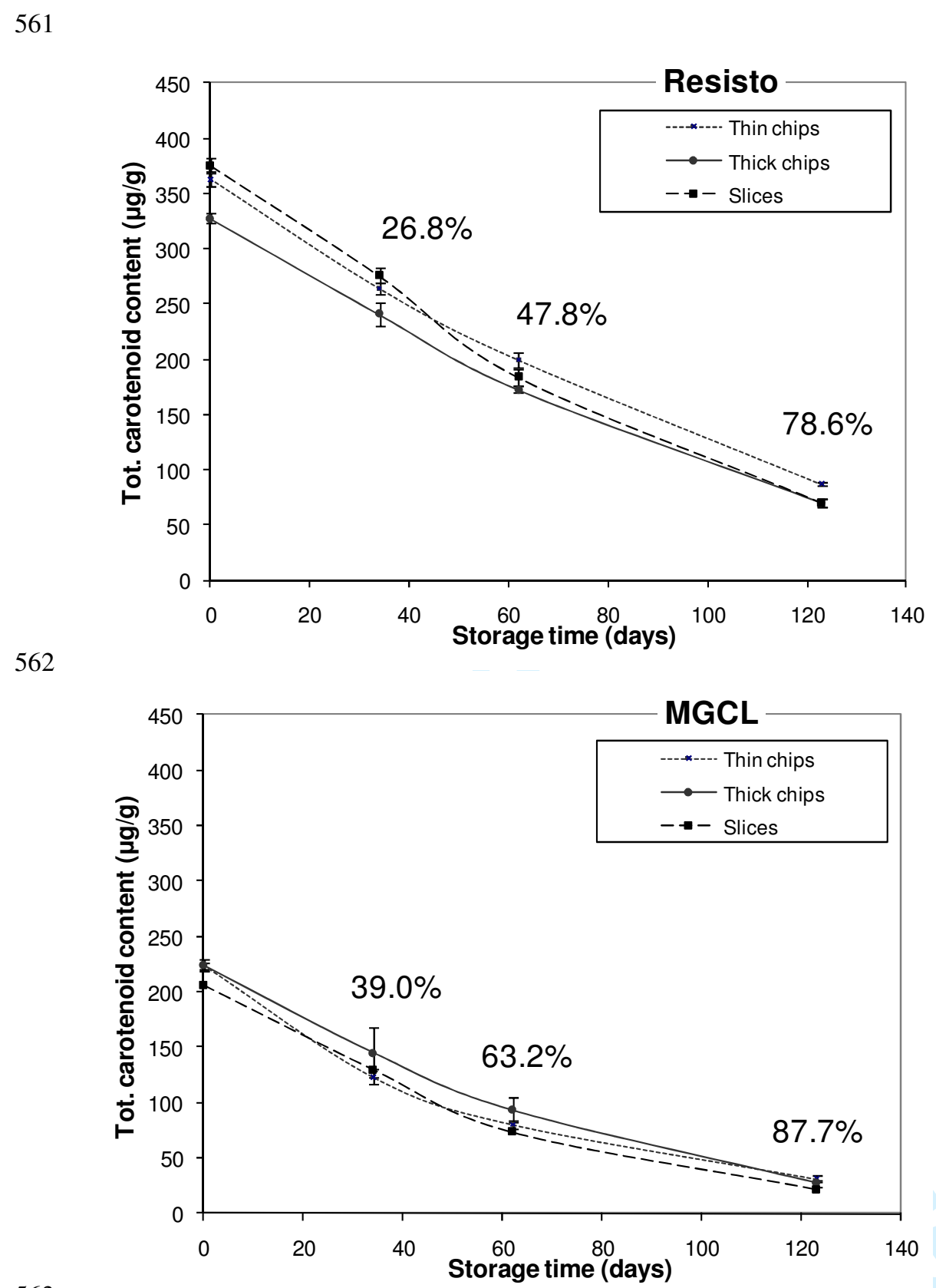

563 Figure 1: Kinetics of total carotenoid degradation during storage of Resisto and 565 MGCL01 varieties chipped to three different sizes. Mean of $2^{2}$ replicate; error bars refer to 566 standard error. 


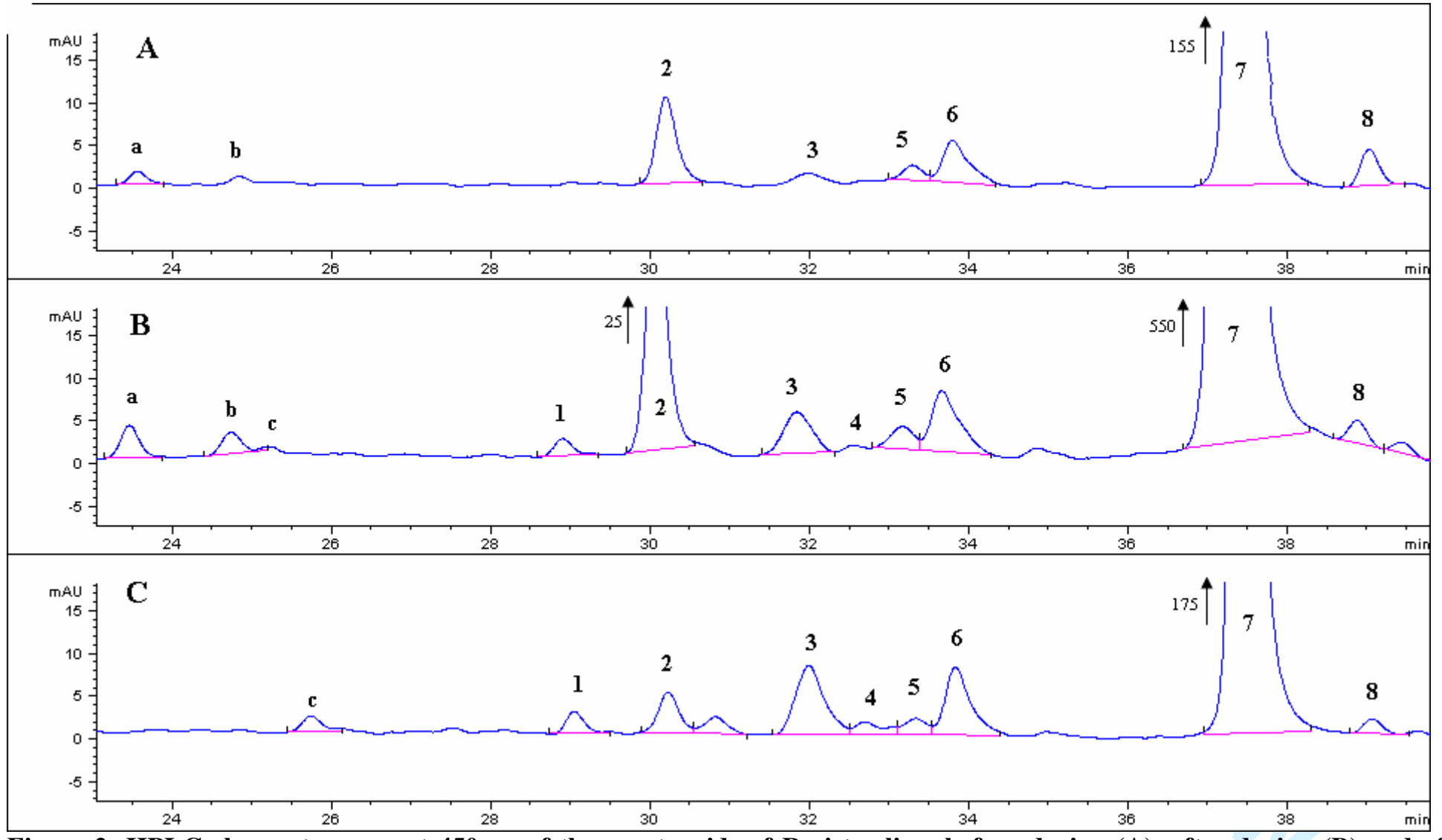

568 Figure 2: HPLC chromatograms at 450nm of the carotenoids of Resisto slices before drying (A), after drying (B) and after 120 days 569 storage (C). a: Possibly $\beta$-carotene-5,6,5',6'-diepoxide $\left(23 \mathrm{~min}\right.$.) $(414 ; \mathbf{4 4 0} ; 468 \mathrm{~nm})$; b: Possibly $\beta$-carotene-5,6,5', $8^{\prime}$-diepoxide $(24 \mathrm{~min}$.) $(400 ; 422 ; 450 \mathrm{~nm})$; c: 570 unidentified (25 min.) (406; 424; 450nm); 1: Possibly 13-cis- $\beta$-carotene-5,6 epoxide (29min.) (main wavelengths: 416; 439; 476nm); 2 : Possibly $\beta$-carotene-5,6 epoxide 571 (30min.) (422;446; 472nm); 3: Possibly $\beta$-carotene-5,8 epoxide (32min.) $(406 ; 428 ; 452 \mathrm{~nm})$; 4\&5: Unidentified; 6:13-cis $\beta$-carotene (34min.) $(338 ; 422 ; 444 ; 472 \mathrm{~nm}) ; 7$ : All572 trans- $\beta$-carotene $(37 \mathrm{~min}$.) $(\mathbf{4 5 2} ; 478 \mathrm{~nm}) ; 8$ : Possibly 9 cis- $\beta$-carotene $(39 \mathrm{~min}$.) $(\mathbf{4 4 6} ; 472 \mathrm{~nm})$. The three graphs are not to the same scale because of differing dry matter 573 contents (respectively $27 \%, 89 \%$ and $87 \%$ ). The graphs have been scaled to illustrate the minor peaks and therefore the larger peaks have been truncated. 


\begin{tabular}{lclll}
\hline Page 25: [1] Deleted & \multicolumn{5}{c}{ ba35 } \\
\hline Dry matter (covariate): & \multicolumn{2}{c}{ no } & yes \\
& & & & \\
Source & df & Mean Square & df & Mean Square \\
\hline Variety (V) & 1 & $109904.20 * *$ & 1 & $78458.84 * *$ \\
Chipper (C) & 2 & $1352.88^{* *}$ & 2 & $1629.99 * *$ \\
Trial (T) & 1 & $514.30^{* *}$ & 1 & 149.53 \\
V x C & 2 & $1872.34 * *$ & 2 & 84.51 \\
V x T & 1 & $396.09 *$ & 1 & 1.51 \\
C x T & 2 & $394.72 * *$ & 2 & 87.09 \\
V x C x T & 2 & 68.59 & 1 & 40.77 \\
Error & 12 & 53.43 & 12 & 53.43 \\
Total & 24 & & 24 & \\
\hline
\end{tabular}

* Significant at $\mathrm{p}<0.05$; 